Marquette University

e-Publications@Marquette

Chemistry Faculty Research and Publications

Chemistry, Department of

$1-1-2008$

\title{
Chiral Ionic Liquids: Synthesis, Properties, and Enantiomeric Recognition
}

Shaofang Yu

Marquette University

Sergey V. Lindeman

Marquette University, sergey.lindeman@marquette.edu

Chieu D. Tran

Marquette University, chieu.tran@marquette.edu

Accepted version. The Journal of Organic Chemistry, Vol. 73, No. 7 (2008): 2576-2591. DOI. (C) 2008 American Chemical Society. Used with permission. 


\section{Marquette University}

\section{e-Publications@Marquette}

\section{Chemistry Faculty Research and Publications/College of Arts and Sciences}

This paper is NOT THE PUBLISHED VERSION; but the author's final, peer-reviewed manuscript. The published version may be accessed by following the link in the citation below.

Journal of Organic Chemistry, Vol. 73, No. 7 (2008): 2576-2591. DOI. This article is (C) American Chemical Society and permission has been granted for this version to appear in ePublications@Marquette. American Chemical Society does not grant permission for this article to be further copied/distributed or hosted elsewhere without the express permission from American Chemical Society.

\section{Chiral lonic Liquids: Synthesis, Properties, and Enantiomeric Recognition}

Shaofang Yu

Department of Chemistry, Marquette University, Milwaukee, WI

Sergey Lindeman

Department of Chemistry, Marquette University, Milwaukee, WI

Chieu D. Tran

Department of Chemistry, Marquette University, Milwaukee, WI

\section{Abstract}

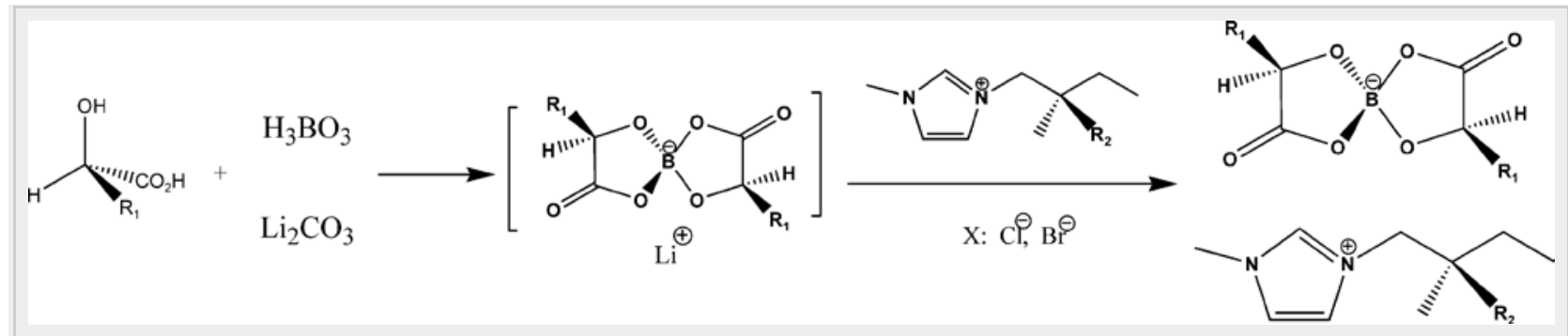

We have synthesized a series of structurally novel chiral ionic liquids which have a either chiral cation, chiral anion, or both. Cations are an imidazolium group, while anions are based on a borate ion with spiral structure and chiral substituents. Both (or all) stereoisomeric forms of each compound in the series can be readily 
synthesized in optically pure form by a simple one-step process from commercially available reagents. In addition to the ease of preparation, most of the chiral ILs in this series are liquid at room temperature with a solid to liquid transformation temperature as low as $-70^{\circ} \mathrm{C}$ and have relatively high thermal stability (up to at least $300^{\circ} \mathrm{C}$ ). Circular dichroism and X-ray crystallographic results confirm that the reaction to form the chiral spiral borate anion is stereospecific, namely, only one of two possible spiral stereoisomers was formed. Results of NMR studies including ${ }^{1} \mathrm{H}\left\{{ }^{15} \mathrm{~N}\right\}$ heteronuclear single quantum coherence (HSQC) show that these chiral ILs exhibit intramolecular as well as intermolecular enantiomeric recognition. Intramolecularly, the chiral anion of an IL was found to exhibit chiral recognition toward the cation. Specifically, for a chiral IL composing with a chiral anion and a racemic cation, enantiomeric recognition of the chiral anion toward both enantiomers of the cation lead to pronounced differences in the NMR bands of the cation enantiomers. The chiral recognition was found to be dependent on solvent dielectric constant, concentration, and structure of the ILs. Stronger enantiomeric recognition was found in solvent with relatively lower dielectric constants $\left(\mathrm{CDCl}_{3}\right.$ compared to $\left.\mathrm{CD}_{3} \mathrm{CN}\right)$ and at higher concentration of ILs. Also, stronger chiral recognition was found for anions with a relatively larger substituent group (e.g., chiral anion with a phenylmethyl group exhibits stronger chiral recognition compared to that with a phenyl group, and an anion with an isobutyl group has the weakest chiral recognition). Chiral anions were also found to exhibit intermolecular chiral recognition. Enantiomeric discrimination was found for a chiral IL composed of a chiral anion and achiral cation toward another chiral molecule such as a quinine derivative.

\section{Introduction}

Ionic liquids (ILS) are a group of organic salts that are liquid at room temperature. ${ }^{1-13}$ They have unique chemical and physical properties, including being air and moisture stable, a high solubility power, and virtually no vapor pressure. ${ }^{1-13}$ Because of these properties, they can serve as a "green" recyclable alternative to the volatile organic compounds that are traditionally used as industrial solvents. ${ }^{1-13}$ The ILs have, in fact, been successfully used in many applications, including replacing traditional organic solvents in organic and inorganic syntheses, solvent extractions, liquid-liquid extractions, and electrochemical reactions as well as medium to enhance the sensitivity of thermal lens measurements. ${ }^{1-13}$ Advances in ILs have made synthesis of chiral ILs a subject of intense study in recent years. ${ }^{14-26}$ The popularity stems from the fact that it is possible to use chiral ILs as chiral solvents for optical resolution, for asymmetric induction in synthesis, as a chiral stationary phase in chromatography, and as both a solvent and chiral selector for the determination of pharmaceutical compounds. ${ }^{14-26}$ However, in spite of their potentials, to date, only a few chiral ILs with limited structure and stereochemistry are reported. Furthermore, their syntheses required rather expensive reagents and elaborate synthesis schemes.

To date, most of the reported ILs are those based on chiral cations. Only a very limited number of chiral ILs contain chiral anions. ${ }^{14-26} \mathrm{~A}$ chiral IL having both a chiral cation and a chiral anion has not been reported. ${ }^{14-26}$ Such a chiral IL is of extreme importance since it will have at least four different optical isomers. Detailed and systematic investigations of chemical and physical properties of these chiral ILs and their isomers will provide insight into effects of chemical structures and stereochemistry of the cation and the anion on properties of ILs; e.g., mp's, solubility, polarity, viscosity, and other physical and chemical properties. Such data will also provide an invaluable tool for the development of molecular models and calculations to predict properties of unknown ILs and to guide the synthesis of novel ILs. Of equal importance is the knowledge gained when this type of chiral IL is used as solvent in asymmetric synthesis and the chiral stationary phase in chromatographic separation. They will provide valuable information on mechanisms of reactions and separations - information which, to date, is not possible since such a chiral solvent is not known. 
Such considerations prompted us to initiate this study, which aims (1) to develop novel and facile synthetic methods for a series of novel and fundamentally important class of chiral compounds, in general, and chiral ILs, in particular. These compounds will have chiral centers not only on the cation but also on the anion as well, (2) to use various spectroscopic methods (NMR, CD, DSC, TGA, MS) to characterize them as well as (3) to determine their enantiomeric recognition.

\section{Results and Discussion}

\section{Synthesis, Properties, and Structure. 1.1. Synthesis.}

Complete synthesis procedures for each IL are described, in detail, in the Supporting Information. In general, as illustrated in Scheme 1, the reaction started with 2-hydroxy-2-R -acetic acid (where $R_{1}$ is methyl, isopropyl, isobutyl, phenyl, phenylmethyl, or cyclohexanyl), boric acid, and lithium carbonate in 2:1:1 molar ratio. After reacting for $1 \mathrm{~h}$ at about $55^{\circ} \mathrm{C}$, the reaction mixture was cooled to room temperature. The product of the first step reaction, lithium borate salt, was not isolated but rather allowed to proceed to the next reaction. For example, either $\mathrm{BMIm}^{+} \mathrm{Cl}^{-}$or $\mathrm{EMIm}^{+} \mathrm{Br}^{-}$or $\mathrm{S}-2-\mathrm{Me}-$

$\mathrm{BMIm}^{+} \mathrm{Br}^{-}$was added to the reaction mixture to induce metathesis reaction between imidazolium salt and lithium borate salt. Depending on the $\mathrm{R}_{1}$ group, the product can be either a solid which precipitated out (when $\mathrm{R}_{1}$ is either phenyl or cyclohexanyl or phenylmethyl group) or a liquid which is miscible with water. Dichloromethane was used to extract the product in both cases.

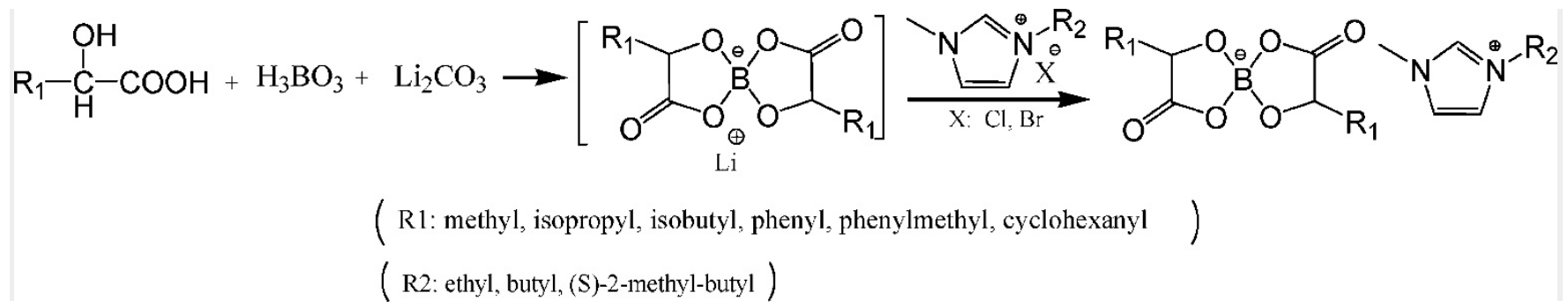

Scheme 1. Shows the General Synthetic Method Used to Synthesize the Chiral ILs

In general, chiral ionic liquids synthesized in this work can be categorically divided into two different classes: (1) those with an achiral cation and chiral anion and (2) those with both a chiral cation and chiral anion. Table 1 lists three cations (or four if both enantiomers of the chiral cation are counted) and six anions (or twelve anions if both enantiomers for each compound are counted) used in this work. There are a total of 48 possible chiral ILs which can be synthesized by appropriately combining these cations and anions. However, instead of synthesizing all possible 48 compounds, our initial synthesis was performed for only one enantiomer for each compound. Determination of physical properties, namely, the solid/liquid transition temperature, of the ILs obtained enabled us to focus our subsequent efforts only on ILs which are liquid at roomtemperature. Table 1 lists 16 ILs which are either liquid at room temperature (first 12 ILs) or of fundamental importance. 
Table 1. Structure and Properties of Chiral Ionic Liquids

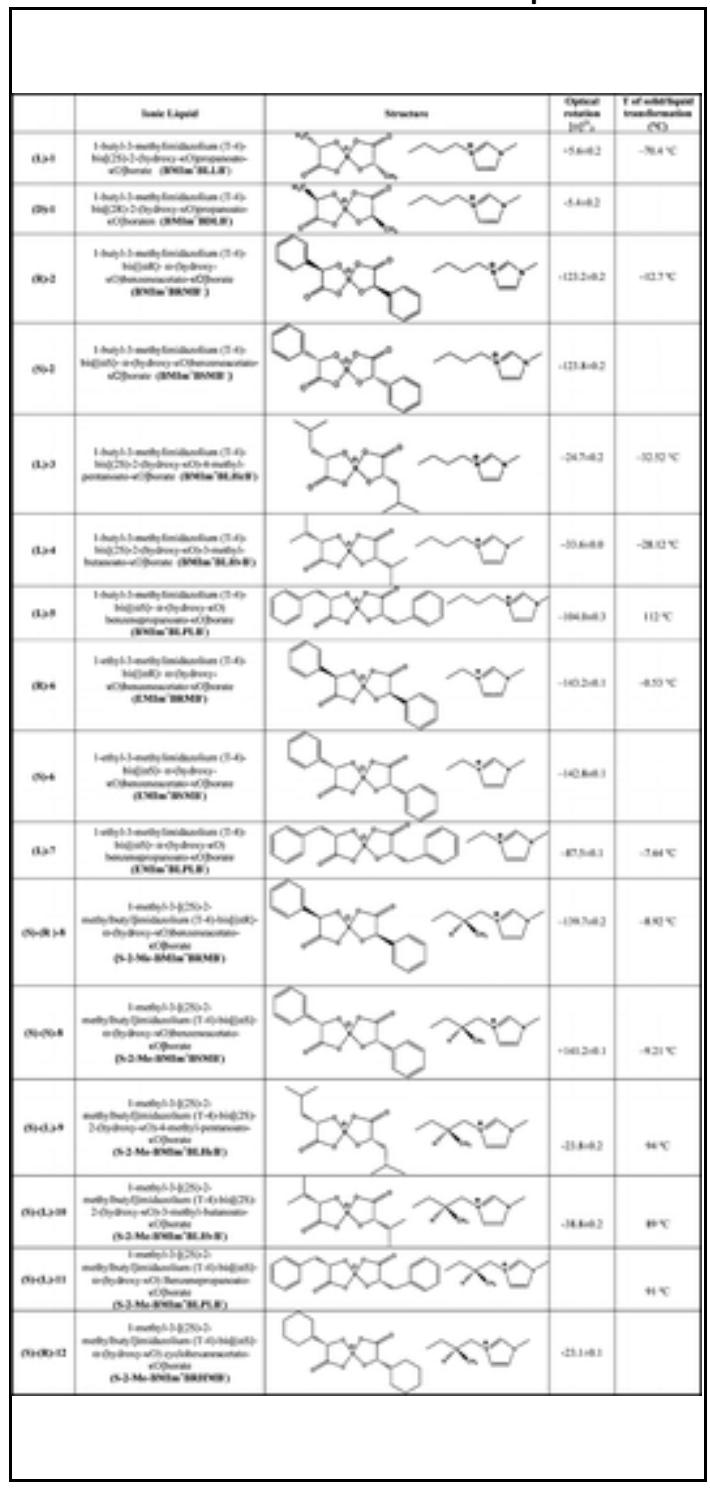

\subsection{Properties.}

All of the 16 ionic liquids synthesized are soluble in polar medium as well as polar solvents including dichloromethane, chloroform, acetone, acetonitrile, and methanol. They are not soluble in nonpolar organic solvents, e.g., hexane and heptane. The solubility of these ionic liquids in water decreases as the $\mathrm{R}_{1}$ group becomes more hydrophobic. When $\mathrm{R}_{1}$ is the methyl, isopropyl, or isobutyl group, the ILs are easily miscible with water but become barely soluble when it is the phenyl, cyclohexanyl, or phenylmethyl group. Attempts have been made, without much success, to prepare EMIm ${ }^{+}$BLLB $^{-}$and $\mathrm{EMIm}^{+} \mathrm{BLHVB}^{-}$. We found that not only the yield of the reactions is low but also products were contaminated with the starting material $\mathrm{EMIm}^{+} \mathrm{Br}^{-}$. These may be due to the fact that solubility of these two ionic liquids in water is relatively higher than in dichloromethane which was used as the extraction solvent in the purification process.

Solid to liquid transformation temperatures $\left(T_{\mathrm{sl}}\right)$ of the ILs were determined using the differential scanning calorimetry (DSC). Results obtained are listed in Table 1. As stated in a previous section, we concentrated our synthetic efforts on ILs which are liquid at room temperature; only a few ILs which 
are solid were listed for comparison. At least 14 ILs were found to be liquid at room temperature with a solid/liquid transformation temperature as low as $-70.4{ }^{\circ} \mathrm{C}$ (see, for example (L)-1 and (D)-1). None of the ILs with $\mathrm{BRHMB}^{-}$as the anion are liquid at room temperature. Regarding cations, all ILs with the chiral S-2-Me-BMIm ${ }^{+}$as the cation are solid at room temperature, except S-2-Me-BMIm ${ }^{+} \mathrm{BRMB}^{-}$and $S-$ 2-Me-BMIm ${ }^{+} B S M B$. However, there does not seem to be a clear correlation between the molecular structure and $T_{\mathrm{sl}}$. For example, $T_{\mathrm{sl}}$ for $\mathrm{BMIm}^{+} \mathrm{BRMB}^{-}$is $-12.7^{\circ} \mathrm{C}$. Replacing the $\mathrm{BMIm}^{+}$with $\mathrm{EMIm}^{+}$led to the increase in the $T_{\mathrm{sl}}$ value to $-0.53^{\circ} \mathrm{C}$. However, the reverse is true when the anion is BLBPB; namely, the $T_{\mathrm{sl}}$ of $\mathrm{EMIm}^{+} \mathrm{BLBPB}^{-}$is $-7.64{ }^{\circ} \mathrm{C}$, but the $\mathrm{BMIm}^{+} \mathrm{BLBPB}^{-}$is a solid at room temperature with $T_{\mathrm{sl}}=112$ ${ }^{\circ} \mathrm{C}$.

Thermal stability of the ILs was investigated using thermal gravimetric analysis (TGA). It was found that all of these ILs are highly thermally stable. Shown in Figure 1 are TGA scans of (L)-1,(R)-2, (S)-(R)-8, (S)$(S)-8,(S)-(L)-9$, and (S)-(L)-10. As illustrated, these chiral ionic liquids are thermally stable up to $250{ }^{\circ} \mathrm{C}$. Even at temperatures as high as $280^{\circ} \mathrm{C}$, they lose only about $1 \%$ of their weights. They retain at least $90 \%$ of their weight at an elevated temperature of $375^{\circ} \mathrm{C}$.

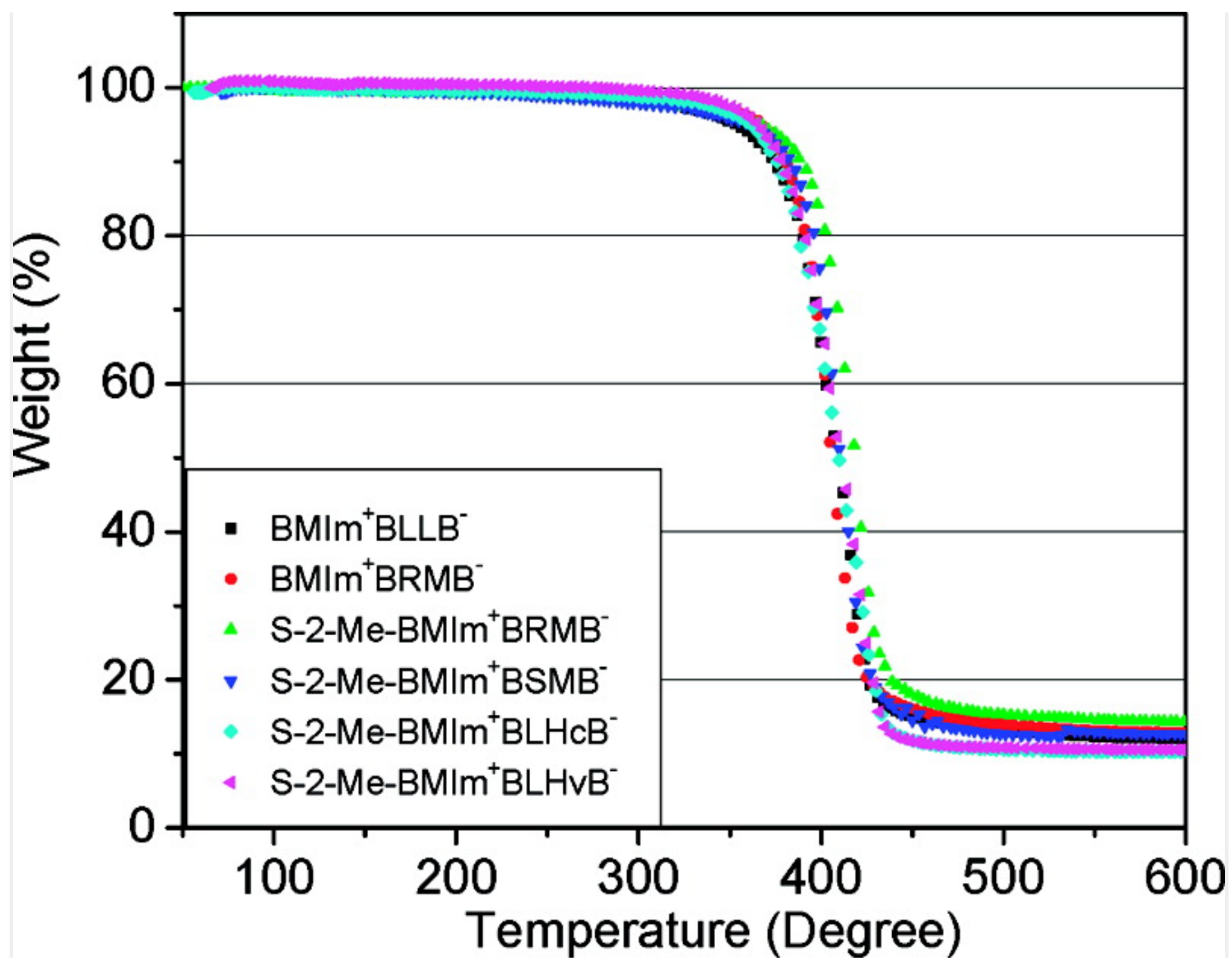

Figure 1 Thermal gravimetric analysis scans of (L)-1 (black -), (R)-2 (red $\mathbf{O}),(\boldsymbol{S})-(\boldsymbol{R})-\mathbf{8}$ (green $\boldsymbol{\Delta}),(\boldsymbol{S})-(\boldsymbol{S})-\mathbf{8}$ (blue v) (S)-(L)-9 (green 1$)$, and (S)-(L)-10 (pink triangle pointing left). 
Mass spectra of the ILs were also taken using electrospray ionization with the detector set for detection of either positive or negative ions. Mass spectra obtained together with detailed information can be found in the Supporting Information. As described in the Supporting Information, the ILs synthesized here exhibit similar behavior as those reported previously. ${ }^{33}$ Specifically, the MS spectra are dominated by aggregations of the ILs. Not only do the ILs undergo extensive aggregations, but also the aggregations were observed for cations as well as for anions. However, in spite of extensive aggregation, each IL can still be detected at $\mathrm{m} / \mathrm{z}$ with either positive or negative ion detection.

\subsection{X-Ray Structure.}

(L)-5 was crystallized from its aqueous solution by slowly evaporating water. Its crystal structure is shown in Figure 2, and its crystallographic parameters and selected bond lengths and angels are listed in Tables 2 and 3. As listed in Table 2, the crystal was solved in monoclinic space group $P 2(1)$ with $Z=2$. The central boron atom is bonded to four oxygen atoms from two molecules of L- $\beta$-phenyllactic acid with two kinds of average B-O distances of 1.5054 (15) $\AA$ and 1.4394 (15) $\AA$. These four oxygen atoms adopt a slightly distorted tetrahedral arrangement about the boron with the angels ranging from $105.15(9)^{\circ}$ to $113.21(9)^{\circ}$. Two distinctly different C-O bond lengths with average distances of 1.3174 (15) $\AA$ and 1.4104 (13) $\AA$ are also shown in the anion. 

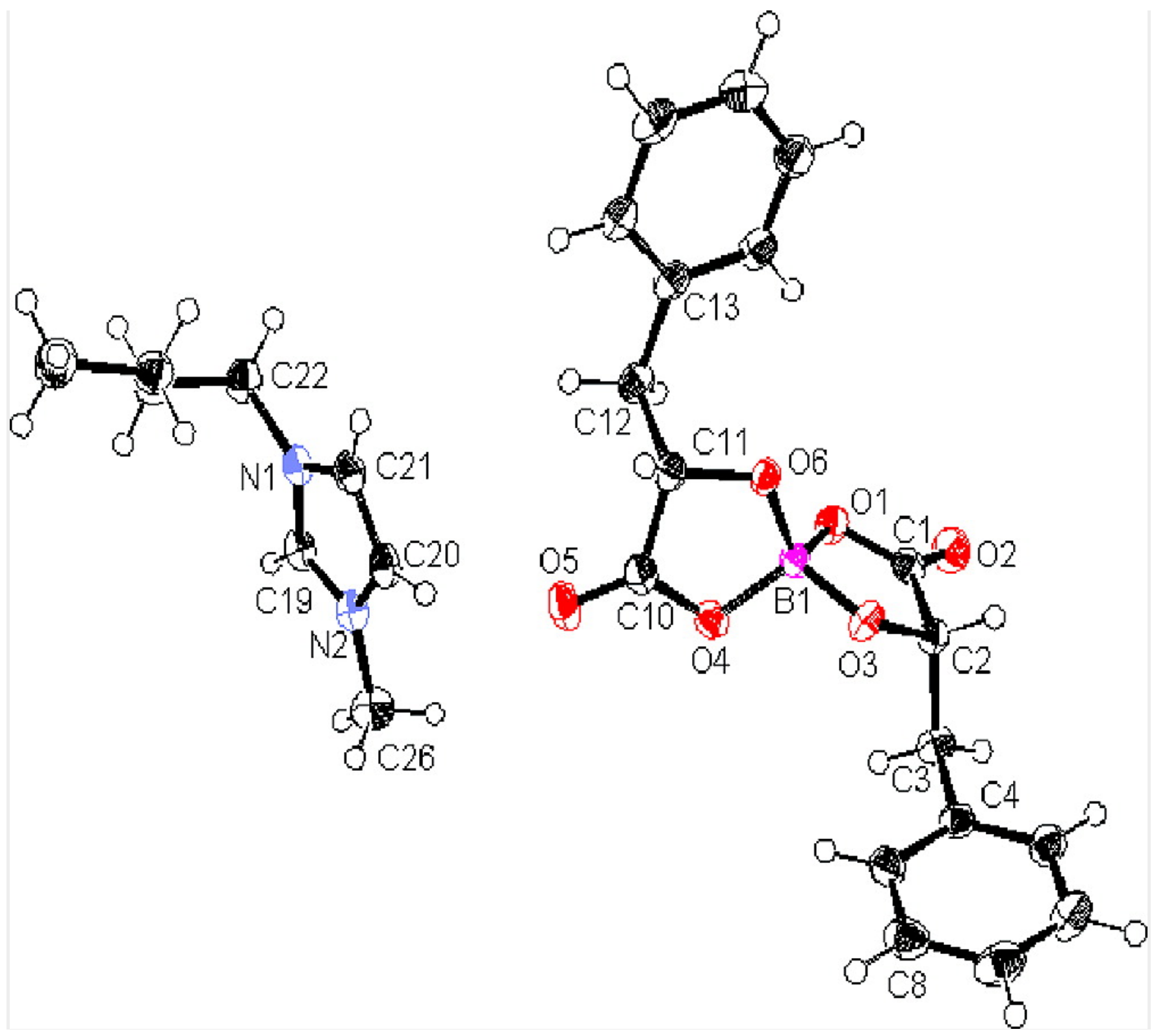

Figure 2 Structure of (L)-5 as drawn by the ORTEP program.

Table 2. Crystal Data and Structure Refinement for (L)-5, (S)-(L)-10, and (D)-5

\begin{tabular}{|llll|}
\hline & (L)-5 & (S)-(L)-10 & (D)-5 \\
Empirical formula & C26 H31 B N2 O6 & C19 H33 B N2 O6 & C26 H31 B N2 O6 \\
Formula weight & 478.34 & 396.28 & 478.34 \\
Temperature & $100(2) \mathrm{K}$ & $100(2) \mathrm{K}$ & $100(2) \mathrm{K}$ \\
Wavelength & $0.71073 \AA$ & $0.71073 \AA$ & $1.54178 \AA$ \\
Crystal system & Monoclinic & Orthorhombic & Monoclinic \\
Space group & $\mathrm{P} 21$ & $\mathrm{P} 212121$ & $\mathrm{P} 21$ \\
Unit cell dimensions & $a=9.3437(8) \AA$ & $a=8.6900(10) \AA$ & $a=9.3360(7) \AA$ \\
& $b=10.8094(9) \AA$ & $b=15.1044(17) \AA$ & $b=10.8109(8) \AA$ \\
\hline
\end{tabular}




\begin{tabular}{|c|c|c|c|}
\hline & $c=13.0215(11) \AA$ & $c=17.1893(19) \AA$ & $c=13.0020(9) \AA$ \\
\hline & $\beta=104.5640(10)^{\circ}$ & & $\beta=104.314(3)^{\circ}$ \\
\hline Volume & $1272.91(19) \AA^{3}$ & $2256.2(4) \AA^{3}$ & $1271.56(16) \AA^{3}$ \\
\hline$Z$ & 2 & 4 & 2 \\
\hline Density (calculated) & $1.248 \mathrm{Mg} / \mathrm{m}^{3}$ & $1.167 \mathrm{Mg} / \mathrm{m}^{3}$ & $1.249 \mathrm{Mg} / \mathrm{m}^{3}$ \\
\hline Absorption coefficient & $0.088 \mathrm{~mm}^{-1}$ & $0.085 \mathrm{~mm}^{-1}$ & $0.719 \mathrm{~mm}^{-1}$ \\
\hline$F(000)$ & 508 & 856 & 508 \\
\hline Crystal size & $0.65 \times 0.2 \times 0.15 \mathrm{~mm}^{3}$ & $0.32 \times 0.28 \times 0.16 \mathrm{~mm}^{3}$ & $0.70 \times 0.45 \times 0.08 \mathrm{~mm}^{3}$ \\
\hline $\begin{array}{l}\theta \text { range for data collecti } \\
\text { on }\end{array}$ & 1.62 to $31.91^{\circ}$ & 1.79 to $31.90^{\circ}$ & 4.89 to $66.72^{\circ}$. \\
\hline Reflections collected & 20587 & 36999 & 10018 \\
\hline Independent reflections & $8096[\mathrm{R}$ (int) $=0.0230]$ & $7400[R$ (int) $=0.0324]$ & $3470[\mathrm{R}$ (int) $=0.0208]$ \\
\hline Absorption correction & $\begin{array}{l}\text { Semiempirical from equiv } \\
\text { alents }\end{array}$ & $\begin{array}{l}\text { Semiempirical from equiv } \\
\text { alents }\end{array}$ & $\begin{array}{l}\text { Semiempirical from equiv } \\
\text { alents }\end{array}$ \\
\hline Refinement method & $\begin{array}{l}\text { Full-matrix least- } \\
\text { squares on } F^{2}\end{array}$ & $\begin{array}{l}\text { Full-matrix least- } \\
\text { squares on } F^{2}\end{array}$ & $\begin{array}{l}\text { Full-matrix least- } \\
\text { squares on } F^{2}\end{array}$ \\
\hline $\begin{array}{l}\text { Data/restraints/parame } \\
\text { ters }\end{array}$ & $8096 / 1 / 316$ & $7400 / 5 / 347$ & $3470 / 1 / 440$ \\
\hline Goodness-of-fit on $F^{2}$ & 1.067 & 1.027 & 0.973 \\
\hline Final R indices $[I>2 \sigma(I)]$ & $\begin{array}{l}\mathrm{R} 1=0.0384, w R 2=0.101 \\
2\end{array}$ & $\begin{array}{l}\mathrm{R} 1=0.0438, w R 2=0.107 \\
1\end{array}$ & $\begin{array}{l}\mathrm{R} 1=0.0215, w R 2=0.056 \\
1\end{array}$ \\
\hline R indices (all data) & $\begin{array}{l}\mathrm{R} 1=0.0425, w R 2=0.104 \\
1\end{array}$ & $\begin{array}{l}\mathrm{R} 1=0.0559, w R 2=0.113 \\
8\end{array}$ & $\begin{array}{l}\mathrm{R} 1=0.0220, w R 2=0.056 \\
4\end{array}$ \\
\hline $\begin{array}{l}\text { Absolute structure para } \\
\text { meter }\end{array}$ & $-0.2(5)$ & $0.5(6)$ & $0.15(10)$ \\
\hline $\begin{array}{l}\text { Largest diff. peak and ho } \\
\text { le }\end{array}$ & 0.457 and -0.176 e. $\AA^{-3}$ & 0.270 and -0.285 e. $\AA^{-3}$ & 0.114 and -0.134 e. $\AA^{-3}$ \\
\hline
\end{tabular}

Table 3. Selected Bond Lengths $[\AA ̊]$ and Angles $\left[{ }^{\circ}\right]$ for (L)-5 and (D)-5

\begin{tabular}{|c|c|c|c|c|}
\hline & (L)-5 & & (D)-5 & \\
\hline $\mathrm{O}(1)-\mathrm{C}(1)$ & $1.3204(15) C(10)-O(4)-B(1)$ & 109.78(9) & $1.3229(18) \mathrm{C}(10)-\mathrm{O}(4)-\mathrm{B}(1)$ & 109.69(10) \\
\hline $\mathrm{O}(1)-\mathrm{B}(1)$ & $1.5049(15) \mathrm{C}(11)-\mathrm{O}(6)-\mathrm{B}(1)$ & $109.50(9)$ & $1.5082(18) \mathrm{C}(11)-\mathrm{O}(6)-\mathrm{B}(1)$ & 109.63(11) \\
\hline $\mathrm{O}(2)-\mathrm{C}(1)$ & $1.2087(15) \mathrm{O}(3)-\mathrm{B}(1)-\mathrm{O}(6)$ & $112.59(9)$ & $1.2148(17) \mathrm{O}(3)-\mathrm{B}(1)-\mathrm{O}(6)$ & $112.99(12)$ \\
\hline $\mathrm{O}(3)-\mathrm{C}(2)$ & $1.4147(13) \mathrm{O}(3)-\mathrm{B}(1)-\mathrm{O}(1)$ & $105.15(9)$ & $1.4179(17) \mathrm{O}(3)-\mathrm{B}(1)-\mathrm{O}(1)$ & 105.01(11) \\
\hline $\mathrm{O}(3)-\mathrm{B}(1)$ & $1.4368(14) \mathrm{O}(6)-\mathrm{B}(1)-\mathrm{O}(1)$ & $113.21(9)$ & $1.4328(19) \mathrm{O}(6)-\mathrm{B}(1)-\mathrm{O}(1)$ & $113.16(11)$ \\
\hline $\mathrm{O}(4)-\mathrm{C}(10)$ & $1.3143(15) \mathrm{O}(3)-\mathrm{B}(1)-\mathrm{O}(4)$ & $113.08(9)$ & $1.3166(17) \mathrm{O}(3)-\mathrm{B}(1)$ & $113.23(11)$ \\
\hline $\mathrm{O}(4)-\mathrm{B}(1)$ & $1.5058(15) \mathrm{O}(6)-\mathrm{B}(1)-\mathrm{O}(4)$ & & $1.5118(19) \mathrm{O}(6)$ & $2(11)$ \\
\hline $\mathrm{O}(5)-\mathrm{C}(10)$ & $1.2117(15) \mathrm{O}(1)-\mathrm{B}(1)-\mathrm{O}(4)$ & $108.25(9)$ & $1.2137(18) \mathrm{O}(1)-\mathrm{B}(1)-\mathrm{O}(4)$ & $108.02(12)$ \\
\hline $\mathrm{O}(6)-\mathrm{C}(11)$ & $1.4060(13) \mathrm{O}(2)-\mathrm{C}(1)-\mathrm{O}(1)$ & $124.59(11)$ & $1.4089(17) \mathrm{O}(2)-\mathrm{C}(1)-$ & $124.41(14)$ \\
\hline $\mathrm{O}(6)-\mathrm{B}(1)$ & $1.4420(15) \mathrm{O}(2)-\mathrm{C}(1)-\mathrm{C}(2)$ & & $1.4423(18) \mathrm{O}(2)-\mathrm{C}(1)-$ & $126.14(14)$ \\
\hline$C(1)-C(2)$ & $1.5252(16) \mathrm{O}(1)-\mathrm{C}(1)-\mathrm{C}(2)$ & $109.25(9)$ & $1.521(2) \quad O(1)-C(1)-C(2)$ & $109.46(11)$ \\
\hline$C(2)-C(3)$ & $1.5270(16) \mathrm{O}(3)-\mathrm{C}(2)-\mathrm{C}(1)$ & $105.05(9)$ & $O(3)-C(2)-C(1)$ & $104.85(11)$ \\
\hline$C(10)-C(11)$ & $1.5226(16) \mathrm{O}(3)-\mathrm{C}(2)-\mathrm{C}(3)$ & 111.94(9) & $1.519(2) \quad O(3)-C(2)-C(3)$ & 111.65(11) \\
\hline
\end{tabular}




\begin{tabular}{|c|c|c|c|c|c|}
\hline 2) & (3) & & $42(2)$ & $C(1)-C(2)-C(3)$ & \\
\hline (1) & $=(2)$ & & $1.3317(1 \mathrm{c}$ & 9)C(4) & \\
\hline 1) & $-\mathrm{O}$ & & 37 & $O(5)-C$ & \\
\hline (1) & 1.47 & $1<5$. & נוצני & 3) $\mathrm{O}(5$ & \\
\hline$v(Z)$ & & & 1.3 & $\mathrm{O}(4)-\mathrm{C}$ & $3(12$ \\
\hline 2) & 1.37 & & 1.37 & $9) \mathrm{O}(6$ & $3(1)$ \\
\hline$V(2)$ & 1.46 & & 1. & 9) $0(6$ & 4(11) \\
\hline$(2$ & 3)C( & & 1.349 & C & 12 \\
\hline$C(1)-O($ & 5(9) & & 10 & 1) $C(1$ & (1) \\
\hline \multicolumn{3}{|c|}{$C(2)-O(3)-B(1) 109.72(8)$} & & & \\
\hline
\end{tabular}

Hydrogen bonding in ionic liquids, which contain an imidazolium ring, have been studied both theoretically and experimentally. ${ }^{7,34-37}$ It has been proposed that the positive charge on the imidazolium ring acidifies or activates the three $\mathrm{C}-\mathrm{H}$ bonds on it $(\mathrm{C} 19-\mathrm{H} 19 \mathrm{a}, \mathrm{C} 20-\mathrm{H} 2 \mathrm{Oa}, \mathrm{C} 21-\mathrm{H} 21 \mathrm{a})$ and two $\mathrm{C}-\mathrm{H}$ bonds which are connected to it (C22-H22a, C22-H22b, C26-H26a, C26-H26b, $\mathrm{C} 26-\mathrm{H} 26 \mathrm{c})$. As a consequence, it is relatively easier for this type of IL to form hydrogen bonds with other electron donor atoms, ${ }^{7,34-37}$ e.g., oxygen atoms. To determine $\mathrm{C}-\mathrm{H} \cdots \mathrm{O}$ hydrogen bonds, $2.7 \AA$ was set up as the cutoff limit for the distance of $\mathrm{H} \cdots \mathrm{O}\left(d_{H} \cdots \mathrm{O}\right)$, and the angle of $\mathrm{C}-\mathrm{H} \cdots \mathrm{O}$ must be bigger than $90^{\circ} .{ }^{38-40}$ Based on this assumption, there are seven kinds of $\mathrm{C}-\mathrm{H} \cdots \mathrm{O}$ hydrogen bonds in the crystal structure of BMIm ${ }^{+}$BLPLB $^{-}$(Table 4). Six of them (No. 1-No. 6 in Table 3) exist between the aforementioned activated $\mathrm{C}-\mathrm{H}$ bonds on the BMIm ${ }^{+}$and oxygen atoms on the anion BLPLB. The seventh (No. 7 in Table 3 ) is between aromatic $\mathrm{C} 8-\mathrm{H} 8 \mathrm{a}$ and $\mathrm{O} 2$. Even though the distance of $\mathrm{O} 4-\mathrm{H} 24 \mathrm{~b}$ is $2.682 \AA$, it was not considered as a hydrogen bond since $\mathrm{C} 24-\mathrm{H} 24 \mathrm{~b}$ is not activated. They were probably brought together by packing of the anions. Both the cation $\mathrm{BMIm}^{+}$and anion BLPLB adopt two different conformations in the crystal. One imidazolium cation interacts with the first borate anion through three hygrogen bonds (No. 1-No. 3) and with the second one through one hydrogen bond which is No. 4 and with the third one through two weak hydrogen bonds (No. 5 and No. 6) whose $\mathrm{H} \cdots \mathrm{O}$ distances are 2.615 and $2.666 \AA$ A. Similarly, one anion interacts with three cations. 02 forms a weak hydrogen bond (No.7) with $\mathrm{H} 8 \mathrm{a}$ which is on an aromatic ring of another anion, and the hydrogen bond results in packing of the aromatic ring in the crystal. Packings of the molecules are shown in Figure 3. 


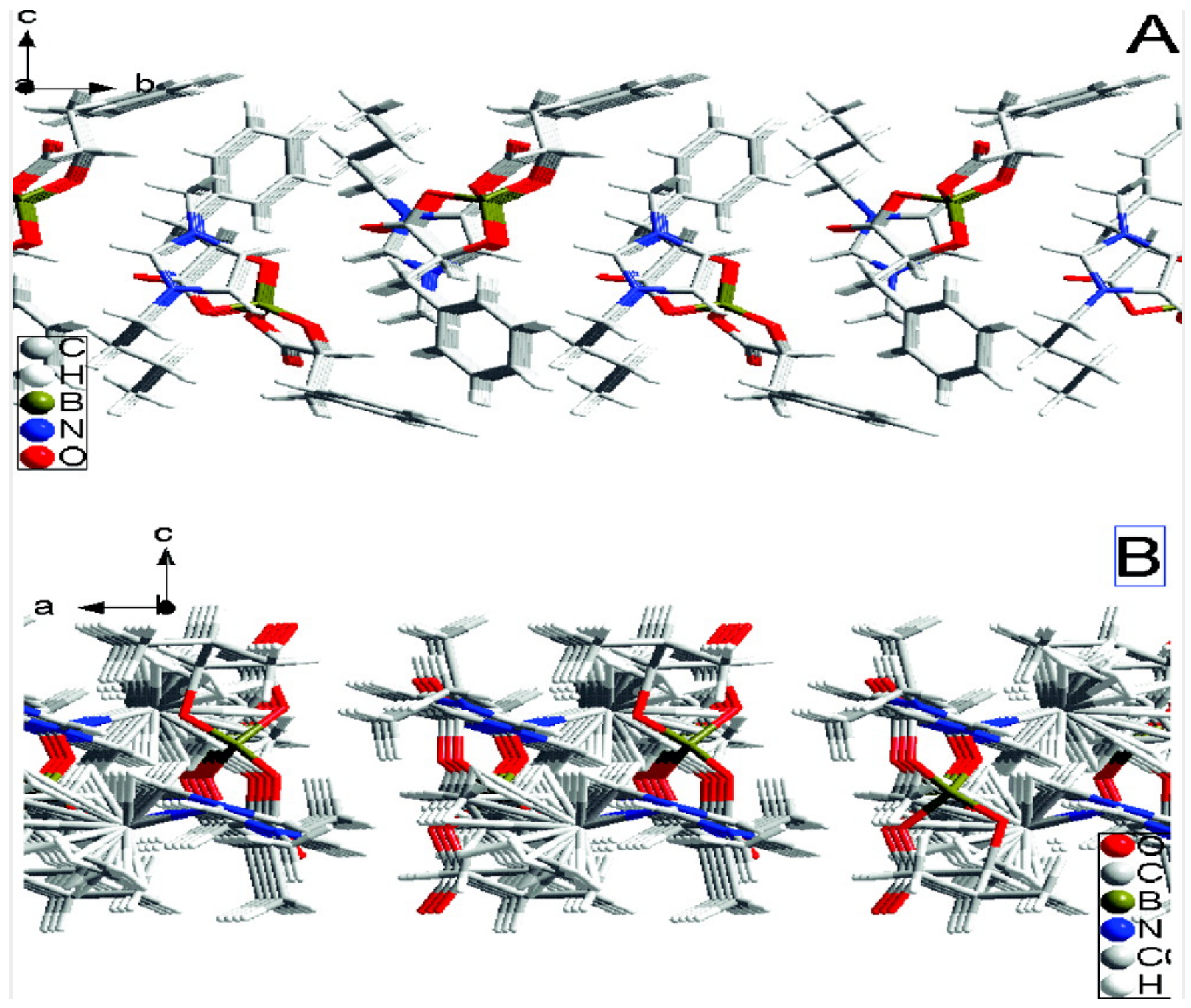

Figure 3 Molecular packing of (L)-5 along $a$ and $b$ axes. 

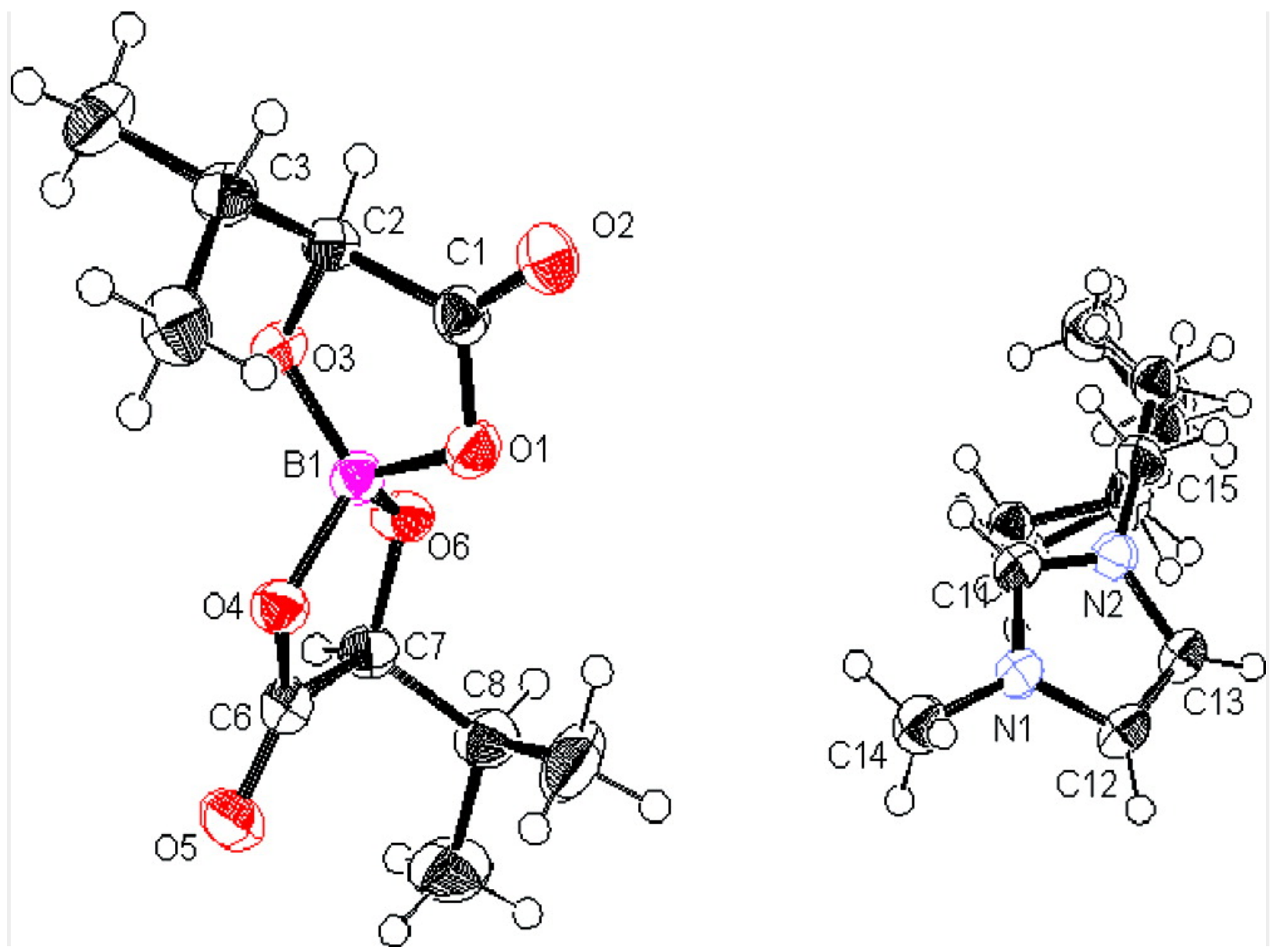

Figure 4 Structure of (S)-(L)-10 drawn by the ORTEP program. 

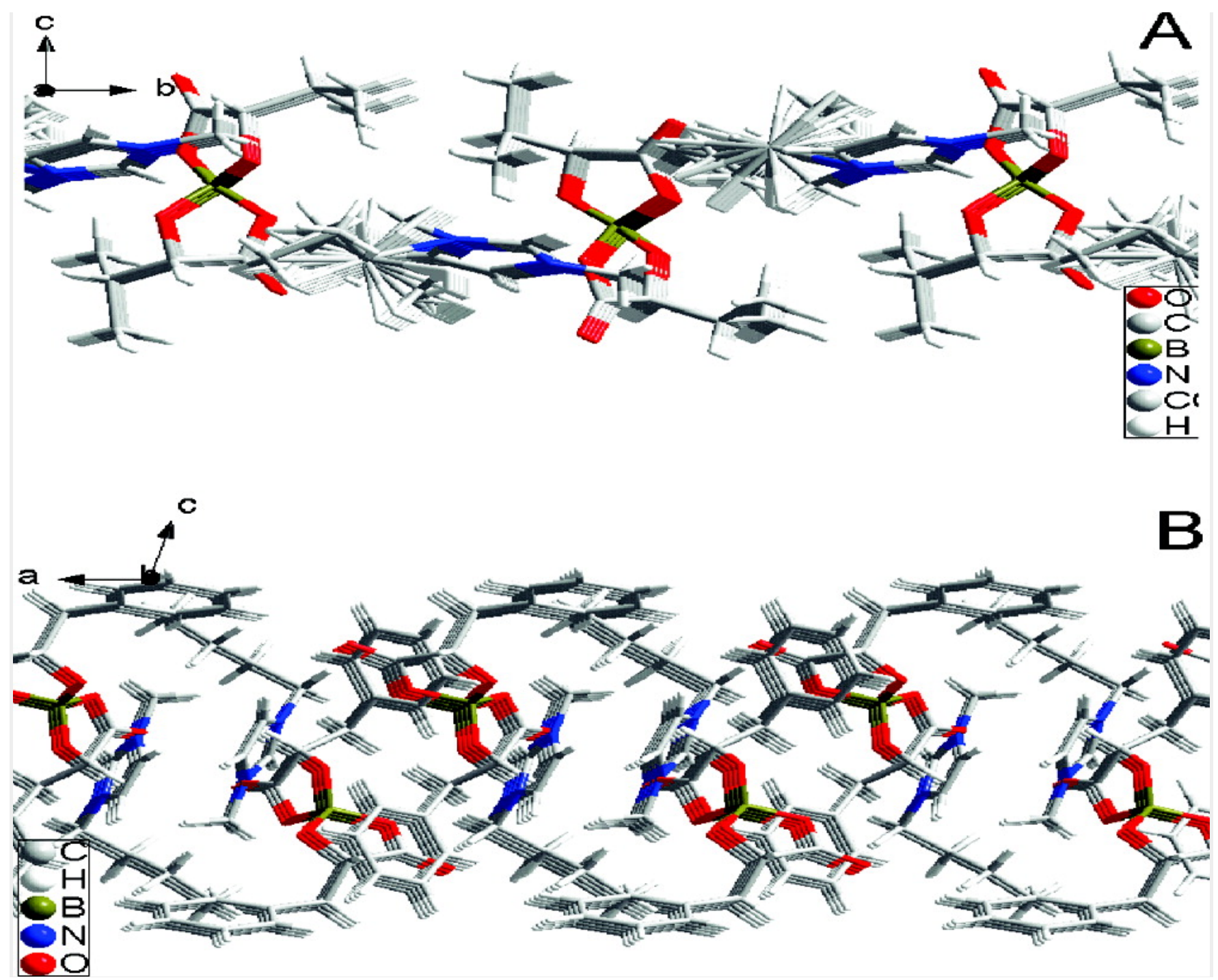

Figure 5 Molecular packing of (L)-5 along $a$ and $b$ axes. 
A rac-2-Me-BMIm ${ }^{+}$BLPLB ${ }^{-100 m M ~ i n ~} \mathrm{CDCl}_{3}$

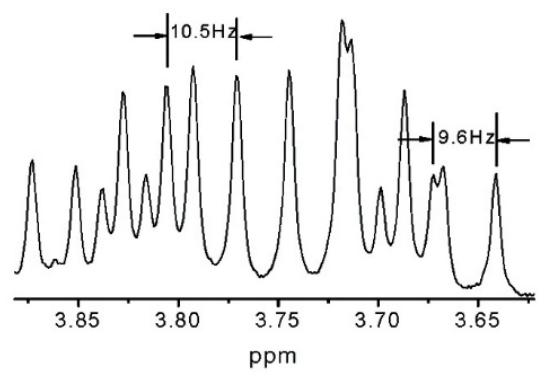

C rac-2-Me-BMIm ${ }^{+} B L P L B^{-}$in $\mathrm{CD}_{3} \mathrm{CN}$

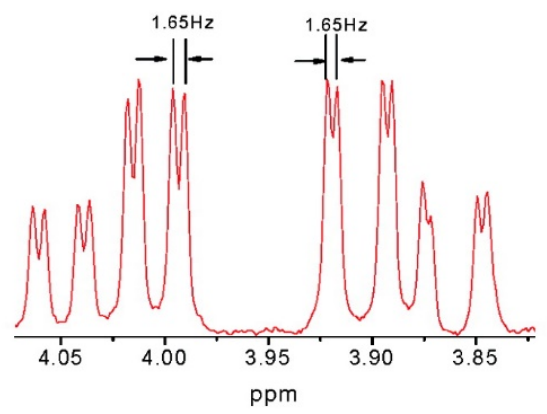

E rac-2-Me-BMIm ${ }^{+} \mathrm{BRHMB}^{-} 50 \mathrm{mM}$ in $\mathrm{CD}_{3} \mathrm{CN}$

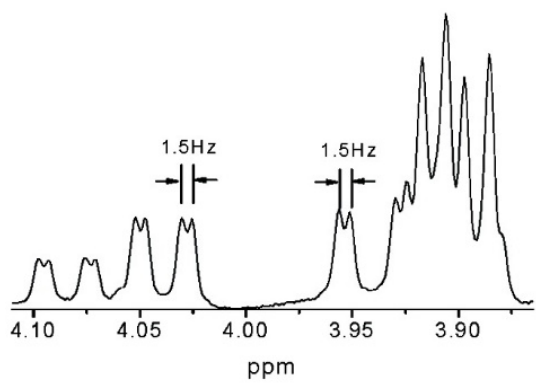

G

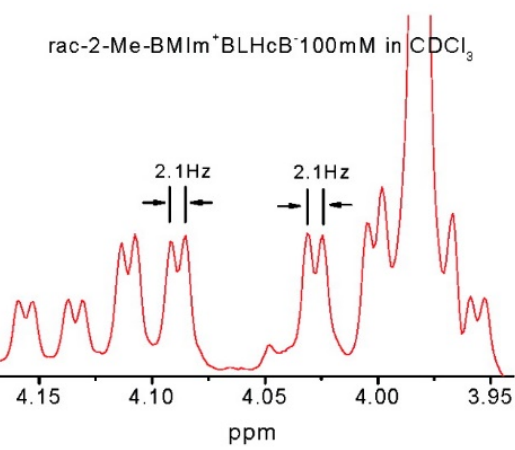

I

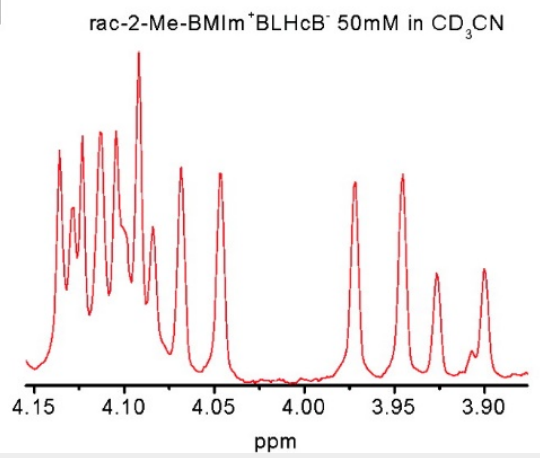

B

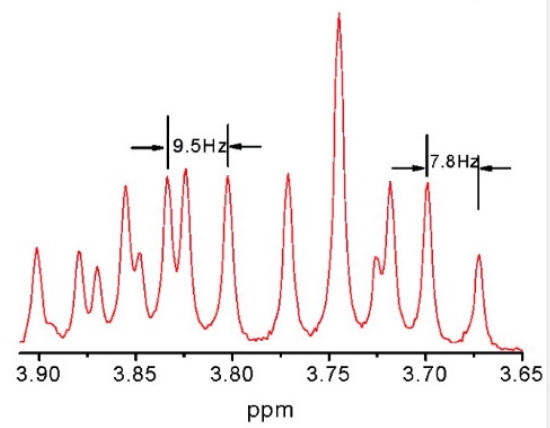

D

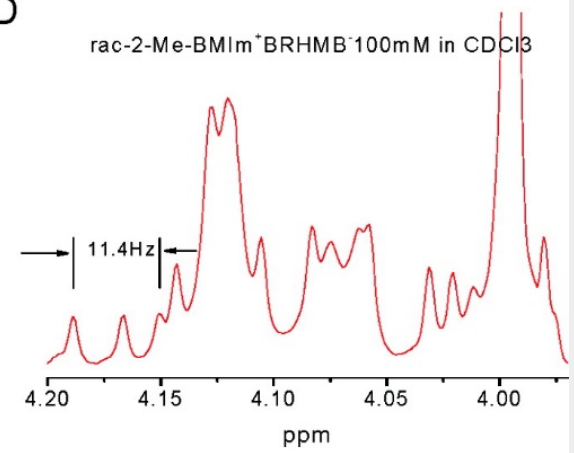

$\mathrm{F}$

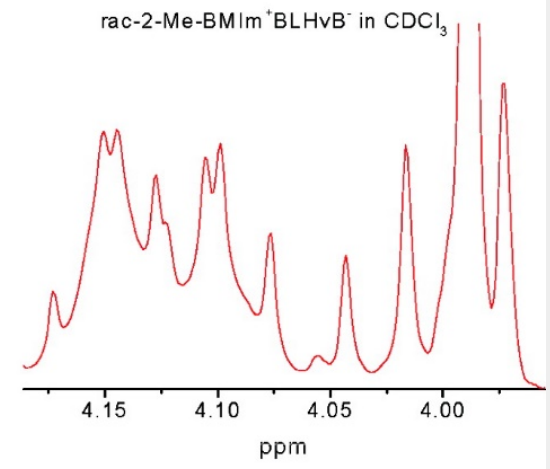

$\mathrm{H}$

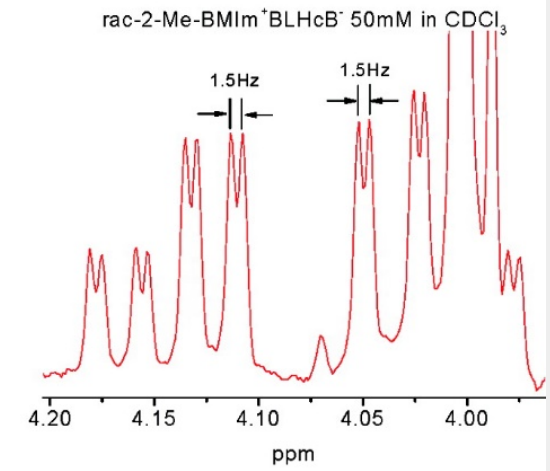

$J$

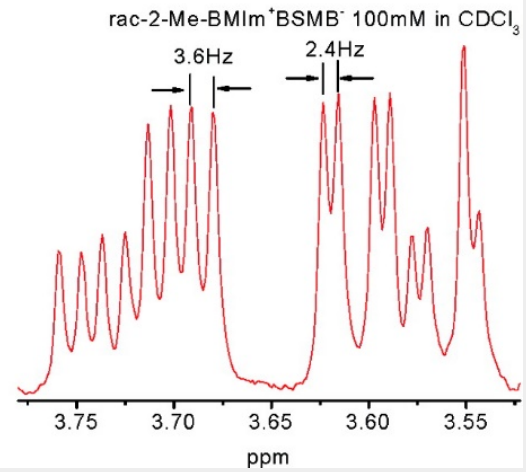




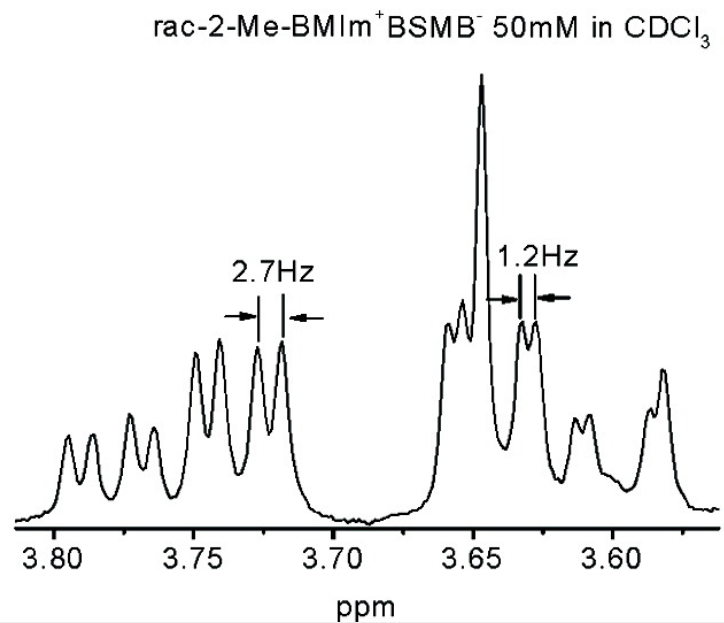

Figure 6 Expanded ${ }^{1} \mathrm{H}$ NMR spectra of $\mathrm{H} 6$ and $\mathrm{H}^{\prime}{ }^{\prime}$ with splitting values labeled.

Table 4. Bond Lengths, Angels, and $\mathrm{C}-\mathrm{O}$ Distances of $\mathrm{C}-\mathrm{H} \cdots \mathrm{O}$ Hydrogen Bonds in the Crystal of (L)-5 and (D)-5

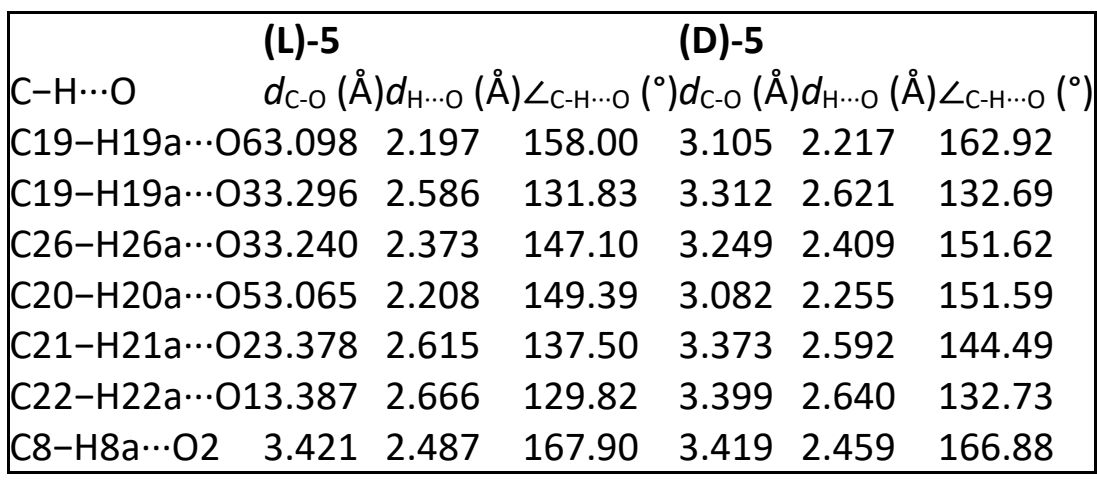

Table 5. Selected Bond Lengths $[\AA]]$ and Angles $\left[{ }^{\circ}\right]$ for $(S)-(L)-10$

\begin{tabular}{|ll|}
\hline $\mathrm{O}(1)-\mathrm{C}(1)$ & $1.3204(16) \mathrm{O}(3)-\mathrm{B}(1)-\mathrm{O}(1) 104.41(10)$ \\
$\mathrm{O}(1)-\mathrm{B}(1)$ & $1.4963(17) \mathrm{O}(4)-\mathrm{B}(1)-\mathrm{O}(1) 108.84(10)$ \\
$\mathrm{O}(2)-\mathrm{C}(1)$ & $1.2119(17) \mathrm{C}(1)-\mathrm{O}(1)-\mathrm{B}(1) 110.48(10)$ \\
$\mathrm{O}(3)-\mathrm{C}(2)$ & $1.4186(15) \mathrm{C}(2)-\mathrm{O}(3)-\mathrm{B}(1) 110.71(10)$ \\
$\mathrm{O}(3)-\mathrm{B}(1)$ & $1.4436(16) \mathrm{C}(6)-\mathrm{O}(4)-\mathrm{B}(1) 110.29(10)$ \\
$\mathrm{O}(4)-\mathrm{C}(6)$ & $1.3237(16) \mathrm{C}(7)-\mathrm{O}(6)-\mathrm{B}(1) 111.11(10)$ \\
$\mathrm{O}(4)-\mathrm{B}(1)$ & $1.4953(16) \mathrm{O}(2)-\mathrm{C}(1)-\mathrm{O}(1) 123.75(12)$ \\
$\mathrm{O}(5)-\mathrm{C}(6)$ & $1.2038(16) \mathrm{O}(2)-\mathrm{C}(1)-\mathrm{C}(2) 126.58(12)$ \\
$\mathrm{O}(6)-\mathrm{C}(7)$ & $1.4087(16) \mathrm{O}(1)-\mathrm{C}(1)-\mathrm{C}(2) 109.67(11)$ \\
$\mathrm{O}(6)-\mathrm{B}(1)$ & $1.4425(16) \mathrm{O}(3)-\mathrm{C}(2)-\mathrm{C}(1) 104.61(10)$ \\
$\mathrm{C}(1)-\mathrm{C}(2)$ & $1.5167(18) \mathrm{O}(3)-\mathrm{C}(2)-\mathrm{C}(3) 113.07(10)$ \\
$\mathrm{C}(6)-\mathrm{C}(7)$ & $1.520(2) \mathrm{C}(1)-\mathrm{C}(2)-\mathrm{C}(3) 112.65(11)$ \\
$\mathrm{N}(1)-\mathrm{C}(11)$ & $1.3233(17) \mathrm{O}(5)-\mathrm{C}(6)-\mathrm{C}(7) 126.55(13)$ \\
\hline
\end{tabular}




\begin{tabular}{|c|c|}
\hline$N(1)-C(12) \quad 1.3743(17$ & $\mathrm{O}(4)-\mathrm{C}(6)-\mathrm{C}(7) 109.56(11)$ \\
\hline$N(2)-C(11) \quad 1.3245(18$ & $\mathrm{O}(6)-\mathrm{C}(7)-\mathrm{C}(6) 104.56(10)$ \\
\hline$N(2)-C(13) \quad 1.3775(1$ & ) $\mathrm{O}(6)-\mathrm{C}(7)$ \\
\hline$C(11)-H(11) 0.872(18)$ & $C(6)-C(7)-C(8) 11$ \\
\hline$C(12)-C(13) 1.346(2)$ & $\mathrm{O}(6)-\mathrm{B}(1)-\mathrm{O}(3) 113.74(11)$ \\
\hline$C(12)-H(12) 0.935(18)$ & $\mathrm{O}(6)-\mathrm{B}(1)-\mathrm{O}(4) 104.37(10)$ \\
\hline$C(13)-H(13) 0.937(15)$ & $\mathrm{O}(3)-\mathrm{B}(1)-\mathrm{O}(4) 113.16(11)$ \\
\hline & $\mathrm{O}(6)-\mathrm{B}(1)-\mathrm{O}(1) 112.44(11)$ \\
\hline
\end{tabular}

Table 6. Bond Lengths, Angels, and $\mathrm{C}-\mathrm{O}$ Distances of $\mathrm{C}-\mathrm{H} \cdots \mathrm{O}$ Hydrogen Bonds in the Crystal Structure of (S)-(L)-10

\begin{tabular}{|c|c|c|}
\hline $\mathrm{C}-\mathrm{H} \cdots \mathrm{O}$ & \multicolumn{2}{|c|}{$d_{\mathrm{C}-\mathrm{O}}(\AA) d_{\mathrm{H} \cdots \mathrm{O}}(\AA) \angle \mathrm{C}-\mathrm{H} \cdots \mathrm{O}\left({ }^{\circ}\right)$} \\
\hline $\mathrm{C} 12-\mathrm{H} 12 \cdots \mathrm{O} 13.136$ & 2.454 & 129.98 \\
\hline $\mathrm{C} 14-\mathrm{H} 14 \mathrm{~b} \cdots \mathrm{O} 13.274$ & 2.662 & 124.42 \\
\hline $3 \cdots 05 \quad 3.208$ & 2.321 & 57 \\
\hline $\mathrm{C} 13-\mathrm{H} 13 \cdots \mathrm{O} 43.467$ & 2.681 & 141.93 \\
\hline $\mathrm{C} 11-\mathrm{H} 11 \cdots \mathrm{O}$ 3.117 & 2.345 & 147.48 \\
\hline C11-H11이 3.221 & 2.437 & 149.53 \\
\hline $\mathrm{C} 15-\mathrm{H} 15 \mathrm{~b} \cdots 063.39$ & 2.563 & 149.52 \\
\hline
\end{tabular}

Crystals of (S)-(L)-10 were obtained after slow evaporation of acetronitrile. Its structure was solved in orthorhombic space group $P 212121$ with $Z=4$ (Table 5). Unlike (L)-5, the 2-methyl-butyl chain on the imidazolium ring is in a disorder state. Its crystal structure unit is shown in Figure 4, and its crystallographic parameters and selected bond lengths and angles are listed in Tables 5 and 6 . The bond lengths and angles around the boron atom are similar to those in (L)-5. Using the same assumptions as those used for (L)-5, there seems to be seven types of $\mathrm{C}-\mathrm{H} \cdots \mathrm{O}$ hydrogen bonds between cations and anions in (S)-(L)-10 (Table 6). No interanionic hydrogen bond was found. Similar to (L)-5, one cation of (S)-(L)-10 in the crystal structure interacts with three anions around it through No. 1 and No. 2 hydrogen bonds, No. 3 and No. 4 hydrogen bonds, and No. 5, No. 6, and No. 7 hydrogen bonds. Both the cation -2-Me-BMIm ${ }^{+}$and anion $\mathrm{BLHVB}^{-}$adopt four different conformations in the crystal. Its structure and packings of the molecules are shown in Figures 4 and 5. 


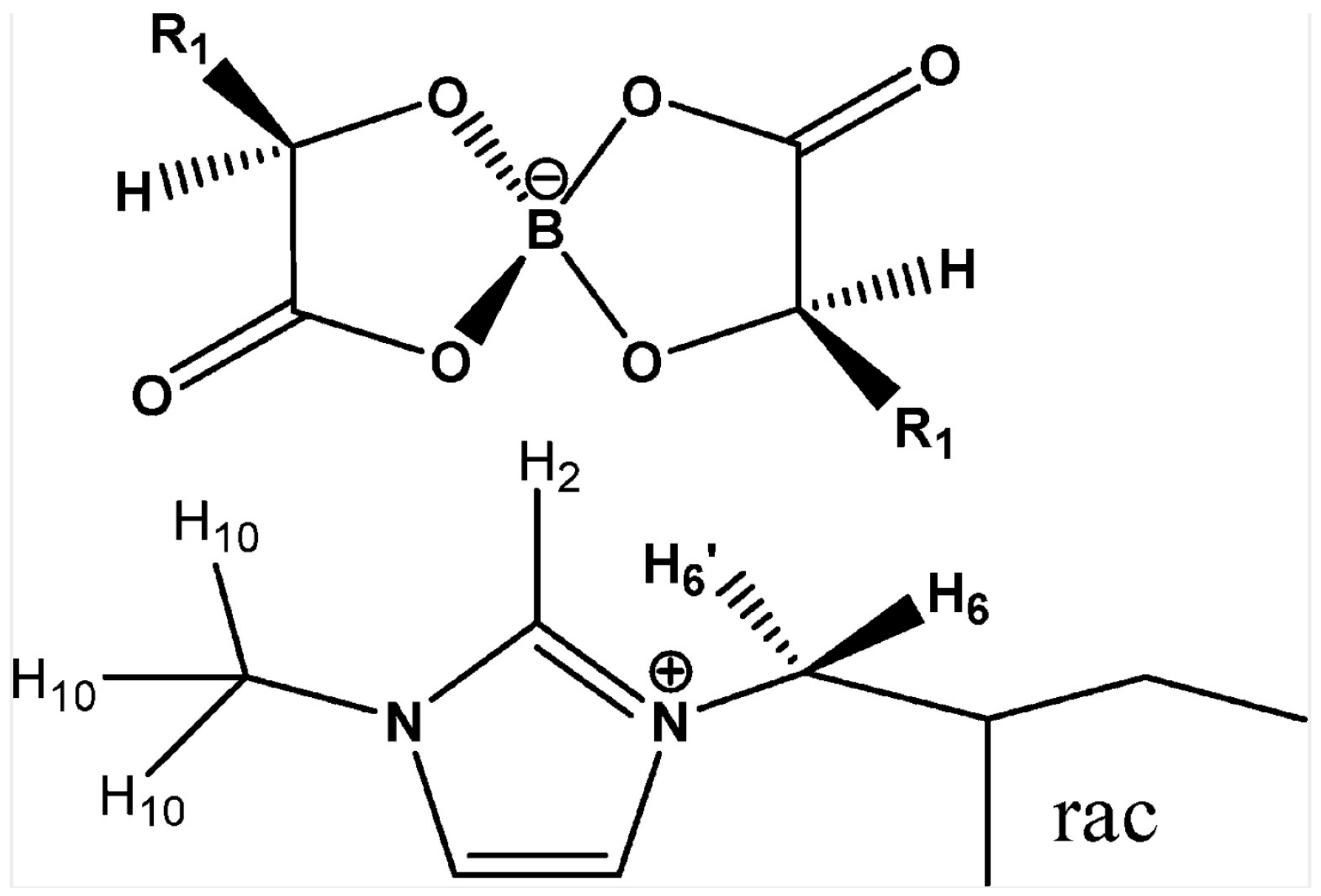

Scheme 2. Structure of a Chiral Ionic Liquid Having a Chiral Anion and a Racemic Cation

Since the center atom boron of all the anions of these chiral ionic liquids is coordinated with two identical unsymmetrical bidentate ligands, a new "Spirane"-like chiral entity is formed of which the configuration can be assigned " $s$ " and " $r$ " descriptors ( $s$ and $r$ were used here to differentiate them from those used to assign the chirality of the cation and anion of the ILs). ${ }^{41,42}$ We have, therefore, performed systematic investigations which aim to determine enantiomers that stem from this chirality. ${ }^{43}$ For (L)-5, it is anticipated that the Spirane-like chiral entity for the anion is a mixture of sand $r$ in a ratio of 1:1 since during reaction the mandelic acid would randomly coordinate with boron. Surprisingly and interestingly, results from X-ray diffraction studies show that this is not the case. The crystals formed after complete evaporation of water are uniform, and its crystal structure shows that this chiral entity is entirely in the s configuration. No r configuration was observed. It is important to add that the experiments were repeated several times, and the same results were observed. To further verify this observation, similar experiments were performed on the enantiomer of (L)-5, i.e., (D)-5. As expected, the crystals of (D)-5 are uniform. Furthermore, not only does the crystal structure have exactly the same cell dimensions as those of (L)-5 but also the crystals are entirely in the $r$ configuration regarding the Spirane chirality. Additionally, its crystal structure shows that (L)-5 and (D)-5 are enantiomers, not diastereomers. If ( $S-s-S)$, where $s$ represents the Spirane-like chiral entity for the anion and $S$ represents the chiral centers of the two ligands, is used to characterize the chiralily of (L)-5, (D)-5 will be $(R-r-R)$. It is pleasing to observe that the Spirane-like chiral entity for the anion of $(S)-(L)-10$ whose crystals were obtained after slow and complete evaporation of acetonitrile is also $s$, which means that it has the same descriptor $(S-S-S)$ as that of (L)-5. It is, therefore, 
evident from the results presented that each of the ILs synthesized in this work has only one stereoisomer on the spirane boron. Efforts have been made to try to obtain crystals of other ILs in a capillary at low temperature, ${ }^{36}$ but with no success.

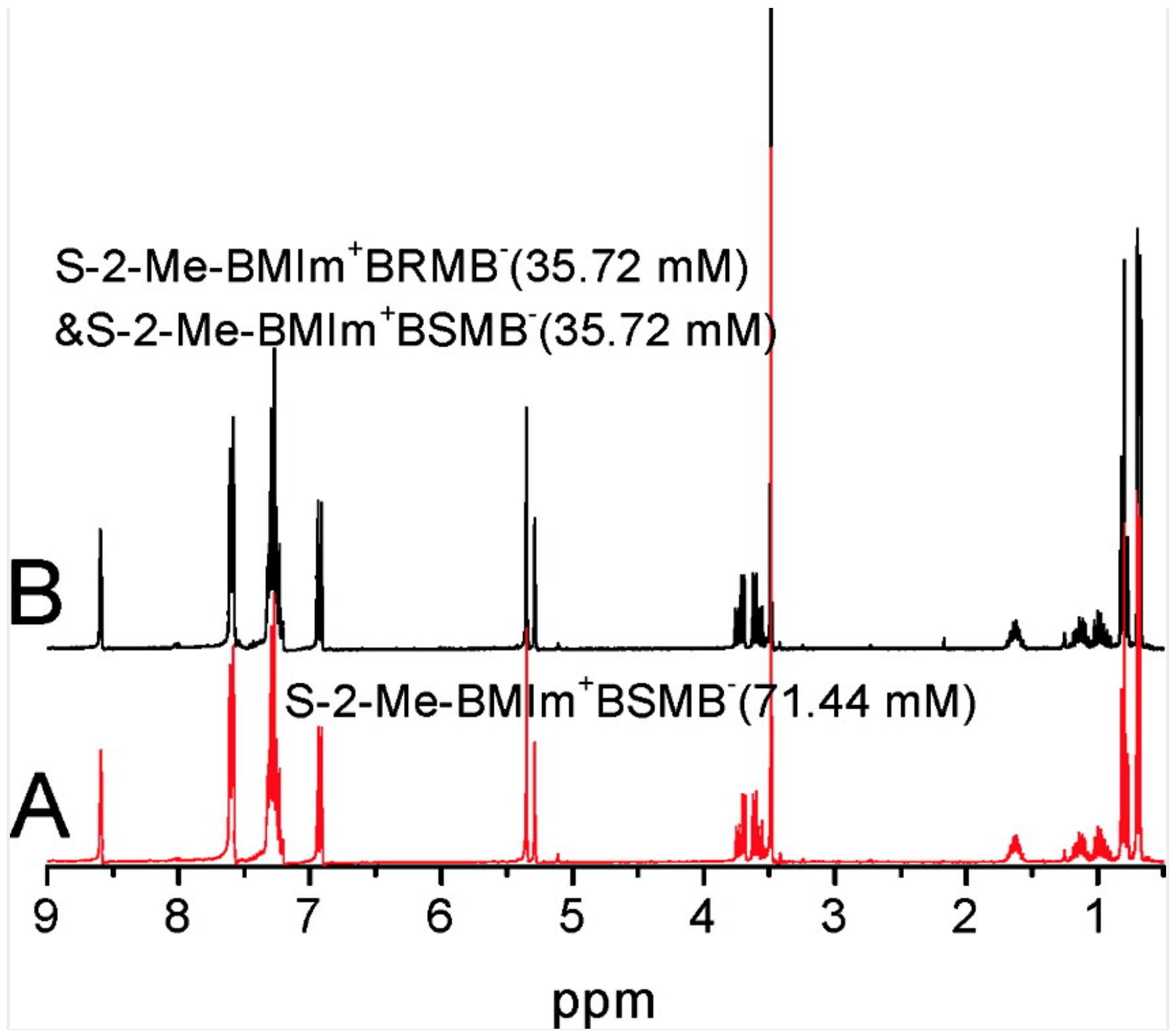

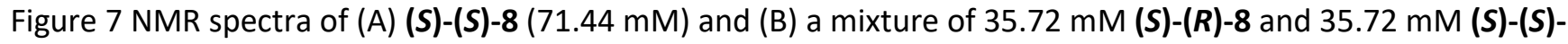
8.

Table 7. Band Splitting Values of $\mathrm{H}_{6}$ and $\mathrm{H}_{6}{ }^{\prime}$ for lonic Liquids with Different Anions

\begin{tabular}{|c|c|c|c|c|c|c|}
\hline & \multicolumn{2}{|c|}{ in $\mathrm{CDCl}_{3}(50 \mathrm{ml}$} & \multicolumn{4}{|c|}{ in $\mathrm{CDCl}_{3}(100 \mathrm{mM})$ in $\mathrm{CD}_{3} \mathrm{CN}(50 \mathrm{mM})$} \\
\hline ionic liquid $\mathrm{R}_{1}$ group & \multicolumn{6}{|c|}{$\Delta \delta \mathrm{H}_{6}(\mathrm{~Hz}) \Delta \delta \mathrm{H}_{6}{ }^{\prime}(\mathrm{Hz}) \Delta \delta \mathrm{H}_{6}(\mathrm{~Hz}) \Delta \delta \mathrm{H}_{6}{ }^{\prime}(\mathrm{Hz}) \Delta \delta \mathrm{H}_{6}(\mathrm{~Hz}) \Delta \delta \mathrm{H}_{6}{ }^{\prime}(\mathrm{Hz})$} \\
\hline$(R, S)-(\mathrm{L})$-10lsopropyl & 0 & 0 & 0 & 0 & -- & -- \\
\hline$(R, S)-(\mathrm{L})-9$ Isobutyl & 1.5 & 1.5 & 2.1 & 2.1 & 0 & 0 \\
\hline$(R, S)-(S)-8$ Phenyl & 2.7 & 1.2 & 3.6 & 2.4 & 0 & 0 \\
\hline \multicolumn{2}{|c|}{$(R, S)-(\mathrm{L})-11$ Phenylmethyl9.5 } & 7.8 & 10.5 & 9.6 & 1.65 & 1.65 \\
\hline
\end{tabular}




\section{Stability of ILs.}

It was reported that some borate-containing compounds may undergo dissociation reaction. To address this possibility, we have performed additional studies which aim to investigate the stability of the chiral ILs under different conditions. The first set of experiments was designed to investigate the stability of the ILs, particularly (S)-2, under different storage conditions; namely, a freshly prepared sample of (S)-2 was divided into several baths, and each of them was kept under different conditions: exposed to laboratory environment $\left(35 \%\right.$ humidity at $25^{\circ} \mathrm{C}$ ) for 19 days and (sample 2 ) for 45 days, (sample 3) stored in a glovebox for 20 days (sample 4), stored under dried air in a desicator for 20 days (sample 5), under argon atmosphere for 20 days (sample 6), and stored under a flowing stream of dried $\mathrm{O}_{2}$ for 27 days (sample 7). As evident from the ${ }^{1} \mathrm{H}$ NMR spectra shown in the Supporting Information, the spectrum of a freshly prepared (S)-2 sample (sample 1) seems to be the same as those of $(\boldsymbol{S})-\mathbf{2}$ samples stored under a flow of dried air, in a glovebox, under flowing dried $\mathrm{O}_{2}$, and under an argon atmosphere even when these samples were kept under these conditions for many days (e.g., 20 days). Conversely, the spectrum of the sample stored under moist air for an extended period of time (19 days or more) is different from the spectrum of the freshly prepared sample (see Supporting Information for spectra); namely, the spectrum of the former has not only new peaks but also chemical shifts that change with time (i.e., chemical shifts are different among three samples (samples 1, 2, and $3)$. These results seem to suggest that compound (S)-2 is stable in dried air, dried $\mathrm{O}_{2}$, and argon but is not stable under air with high moisture. To address the stability of the chiral ILs in water, we compared ${ }^{1} \mathrm{H}$ NMR spectra of $(\boldsymbol{S})-2$ freshly dissolved in a mixture of $60: 40 \mathrm{CD}_{3} \mathrm{CN}: \mathrm{D}_{2} \mathrm{O}$ solvent (sample 1 ) to that of the same sample but under argon for 1 day (sample 2) and for 3 days (sample 3). Because there is no difference among spectra of these samples (spectra are listed in the Supporting Information), the chiral IL (S)-2 seem sto be stable in water. Taken together, the results presented seem to indicate that the chiral ILs, particularly (S)-2, are stable under dried air, dried $\mathrm{O}_{2}$, or argon as well as in water. They may not be stable when stored for an extended period (many days) under conditions where both water and air are present (i.e., air with high humidity). 


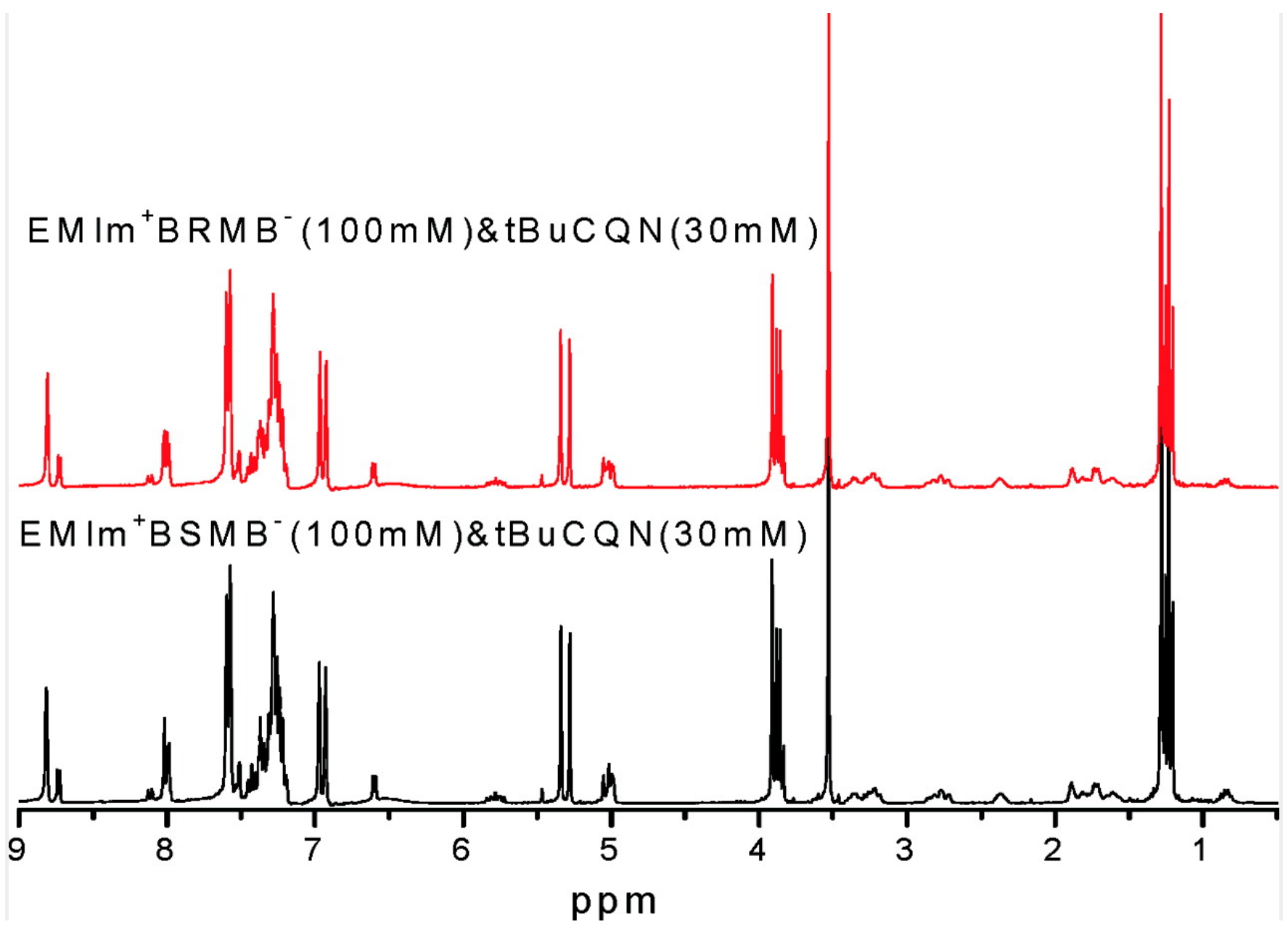

Figure 8 NMR spectra of (A) a mixture of $100 \mathrm{mM}(\boldsymbol{R})-6$ and $30 \mathrm{mM} t \mathrm{BuCQN}$; and (B) a mixture of $100 \mathrm{mM}(\mathrm{S})$ 6 and $30 \mathrm{mM}$ of $t$ BuCQN.

Table 8. ${ }^{1} \mathrm{H}$ NMR Chemical Shifts of $t \mathrm{BuCQN} \cdot \mathrm{HCl},(\mathbf{R})-2 / t \mathrm{BuCQN} \cdot \mathrm{HCl}$, and(S)$2 / t \mathrm{BuCQN} \cdot \mathrm{HCl}$ and Chemical Shift Changes upon Forming Complexes withtBuCQN$\cdot \mathrm{HCl}$

\begin{tabular}{|c|c|c|c|c|}
\hline \multicolumn{5}{|c|}{$\delta(t B u C Q N \cdot H C l) \delta(R)-2 /(t B u C Q N \cdot H C l) \delta(S)-2 /(t B u C Q N \cdot H C l) \Delta \delta(R)-2 /(t B u C Q N \cdot H C l) \Delta \delta(S)-2 / t B u C Q N \cdot H C l$} \\
\hline $\mathrm{H}_{2} 8.834$ & 8.639 & 8.390 & 0.195 & 0.444 \\
\hline $\mathrm{H}_{3} 8.386$ & 8.202 & 8.176 & 0.184 & 0.210 \\
\hline$H_{5} 8.028$ & 7.892 & 7.866 & 0.136 & 0.162 \\
\hline$H_{7} 5.825$ & 6.395 & 6.860 & -0.570 & -1.035 \\
\hline $\mathrm{H}_{12} 5.636$ & 5.524 & 5.500 & 0.112 & 0.136 \\
\hline $\mathrm{H}_{144.238}$ & 4.128 & 4.093 & 0.110 & 0.145 \\
\hline
\end{tabular}

\section{Intramolecular Chiral Recognition: Enantiomeric Recognition of} Chiral Anions.

The enantiomeric recognition ability of ionic liquids is an important factor to determine whether they can be effectively used as chiral solvents, ${ }^{18,23}$ chiral catalysts, a chiral selector for CE, and/or chiral 
stationary phase in GC. ${ }^{18}$ Experiments were designed to determine if chiral anions of the chiral ionic liquids have any chiral recognition ability. They were accomplished by analyzing NMR spectra of ionic liquids composed of chiral anions and a racemic 1-methyl-3-(2-methyl-butyl) imidazolium cation (i.e.,

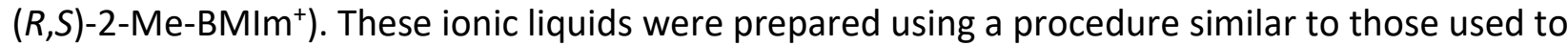
synthesize corresponding chiral ILs containing both a chiral anion and a chiral cation, but in this case, the racemic $(R, S)-2-\mathrm{Me}-\mathrm{BMIm}^{+} \mathrm{Cl}^{-}$was used in the metathesis reaction instead of the optically active S-2-Me-BMIm ${ }^{+} \mathrm{Br}^{-}$. Scheme 2 shows a general structure of a chiral IL having a chiral anion and a racemic cation whose hydrogen atoms are labeled. Figure $6 \mathrm{~A}$ shows three NMR spectra of $(\boldsymbol{R}, \boldsymbol{S})-(\mathrm{L})$ 11 in two different solvents $\left(\mathrm{CD}_{3} \mathrm{CN}\right.$ and $\left.\mathrm{CDCl}_{3}\right)$ and three different concentrations $\left(50 \mathrm{mM}\right.$ in $\mathrm{CD}_{3} \mathrm{CN}$ (top), $50 \mathrm{mM}$ in $\mathrm{CDCl}_{3}$ (middle), and $100 \mathrm{mM}$ in $\mathrm{CDCl}_{3}$ (bottom)). As shown in the spectra, interactions

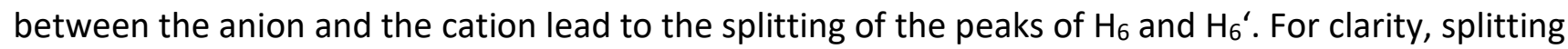
values for these two protons are labeled in the figure. Interestingly, it seems that the splittings are dependent not only on the type of solvent but also on the concentration of the IL. A larger splitting value was found in $\mathrm{CDCl}_{3}\left(9.5\right.$ and $7.8 \mathrm{~Hz}$ ) compared to that in $\mathrm{CD}_{3} \mathrm{CN}$ (1.65 and $1.65 \mathrm{~Hz}$ ). Increasing the IL concentration from 50 (in $\mathrm{CDCl}_{3}$ ) to $100 \mathrm{mM}$ also leads to an increase in the splitting (from 9.5 and $7.8 \mathrm{~Hz}$ to 10.5 and $9.6 \mathrm{~Hz}$, respectively). It is important to add that these observations are not specific to $(R, S)-(L)-11$ but are general for other ILs as well. Figure 6B-D shows NMR spectra of the other three ILs, $(\boldsymbol{R}, \boldsymbol{S})$-(L)-9 (Figure 6B), (R,S)-(S)-8 (Figure 6C), and (R,S)- (S)-12 (Figure 6D), in two different solvents $\left(\mathrm{CD}_{3} \mathrm{CN}\right.$ and $\left.\mathrm{CDCl}_{3}\right)$ and at two different concentrations (50 and $\left.100 \mathrm{mM}\right)$. For clarity, the splitting values for all ILs are listed in Table 7. As listed in the table, in all cases, higher splitting values were found in solvent with relatively lower dielectric constant $\left(\mathrm{CDCl}_{3}\right)$ and at higher IL concentration. Furthermore, the same solvent at the same concentration IL whose $\mathrm{R}_{1}$ group is more bulkly produces larger splitting. For example, at $50 \mathrm{mM}$ in $\mathrm{CDCl}_{3}$, the splitting values in $(\boldsymbol{R}, \boldsymbol{S})$-(L)-11 which has the relatively largest $R_{1}$ group (phenylmethyl) are 9.5 and $7.8 \mathrm{~Hz}$ which are much larger than the values of 2.7 and $1.2 \mathrm{~Hz}$ found for $(\boldsymbol{R}, \boldsymbol{S})-(\mathrm{S})-8\left(\mathrm{R}_{1}=\right.$ phenyl) and 1.5 and $1.5 \mathrm{~Hz}$ found for $(\boldsymbol{R}, \boldsymbol{S})-(\mathrm{L})-\mathbf{9}\left(\mathrm{R}_{1}=\right.$ isobutyl). Since $\mathrm{CDCl}_{3}$ has a relatively lower dielectric constant (4.81) than $\mathrm{CD}_{3} \mathrm{CN}$ (37.5), the results seem to indicate that an ion pair is formed between the anion and the cation of the $\mathrm{IL}$ and that the ion pair formation is stronger in a solvent with lower dielectric constant $\left(\mathrm{CDCl}_{3}\right)$. This, in turn, will bring the anion closer to the cation and make their interaction stronger and, hence, produce larger splitting values. 

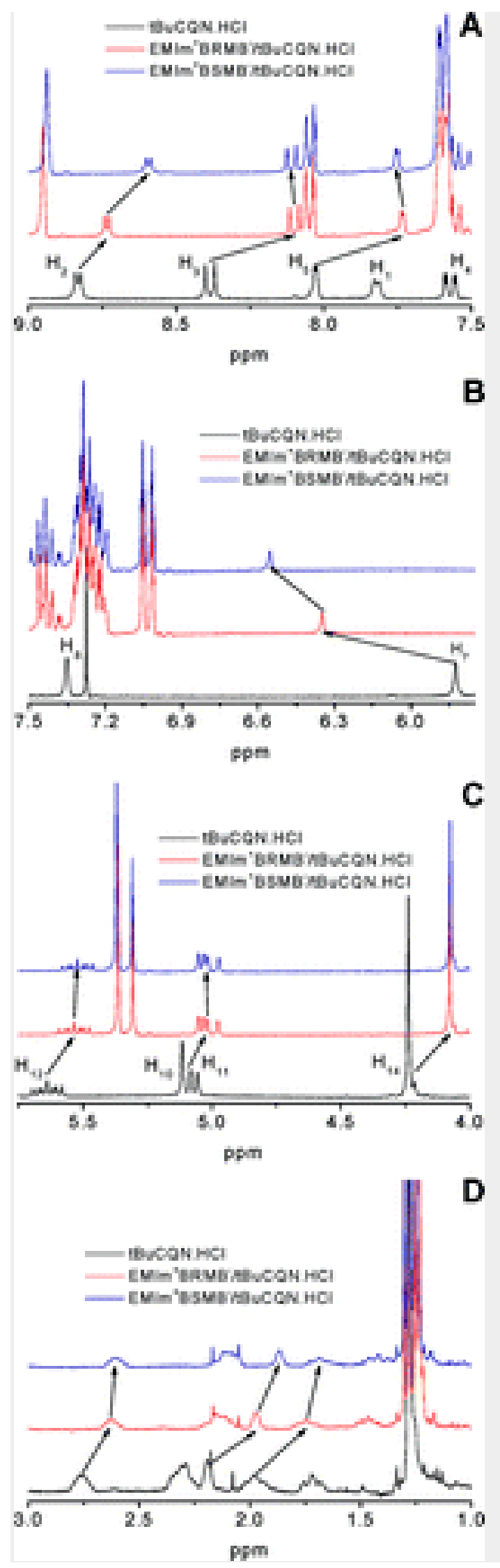

Figure $9 \mathrm{NMR}$ spectra of (top) $30 \mathrm{mM} t \mathrm{BuCQN} \cdot \mathrm{HCl}$; (middle) a mixture of $30 \mathrm{mM} t \mathrm{BuCQN} \cdot \mathrm{HCl}$ and $100 \mathrm{mM}(\boldsymbol{R})-6$, and (bottom) a mixture of $30 \mathrm{mM} t \mathrm{BuCQN} \cdot \mathrm{HCl}$ and $100 \mathrm{mM}(S)-6$ with arrows showing shifts of chemical shifts. 


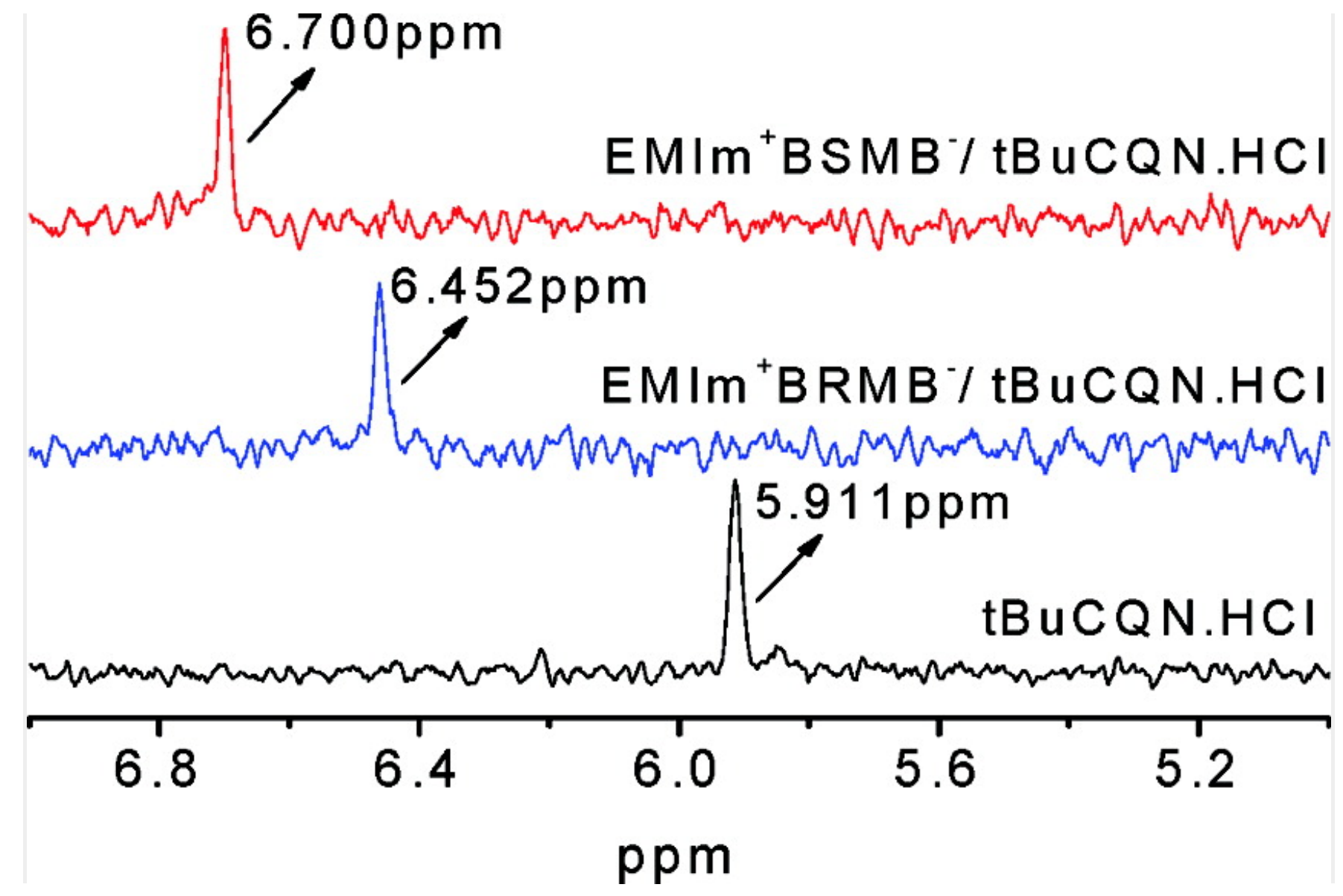

Figure $101 \mathrm{D}{ }^{1} \mathrm{H}\left\{{ }^{15} \mathrm{~N}\right\} \mathrm{HSQC}$ NMR spectra of (bottom) $40 \mathrm{mM}$ tBuCQN$\cdot \mathrm{HCl}(40 \mathrm{mM})$; (middle) a mixture of 40 $\mathrm{mM}(\boldsymbol{R})-6$ and $40 \mathrm{mM} t \mathrm{BuCQN} \cdot \mathrm{HCl}$; and (top) a mixture of $40 \mathrm{mM}(S)-6$ and $40 \mathrm{mM} t \mathrm{BuCQN} \cdot \mathrm{HCl}$. 

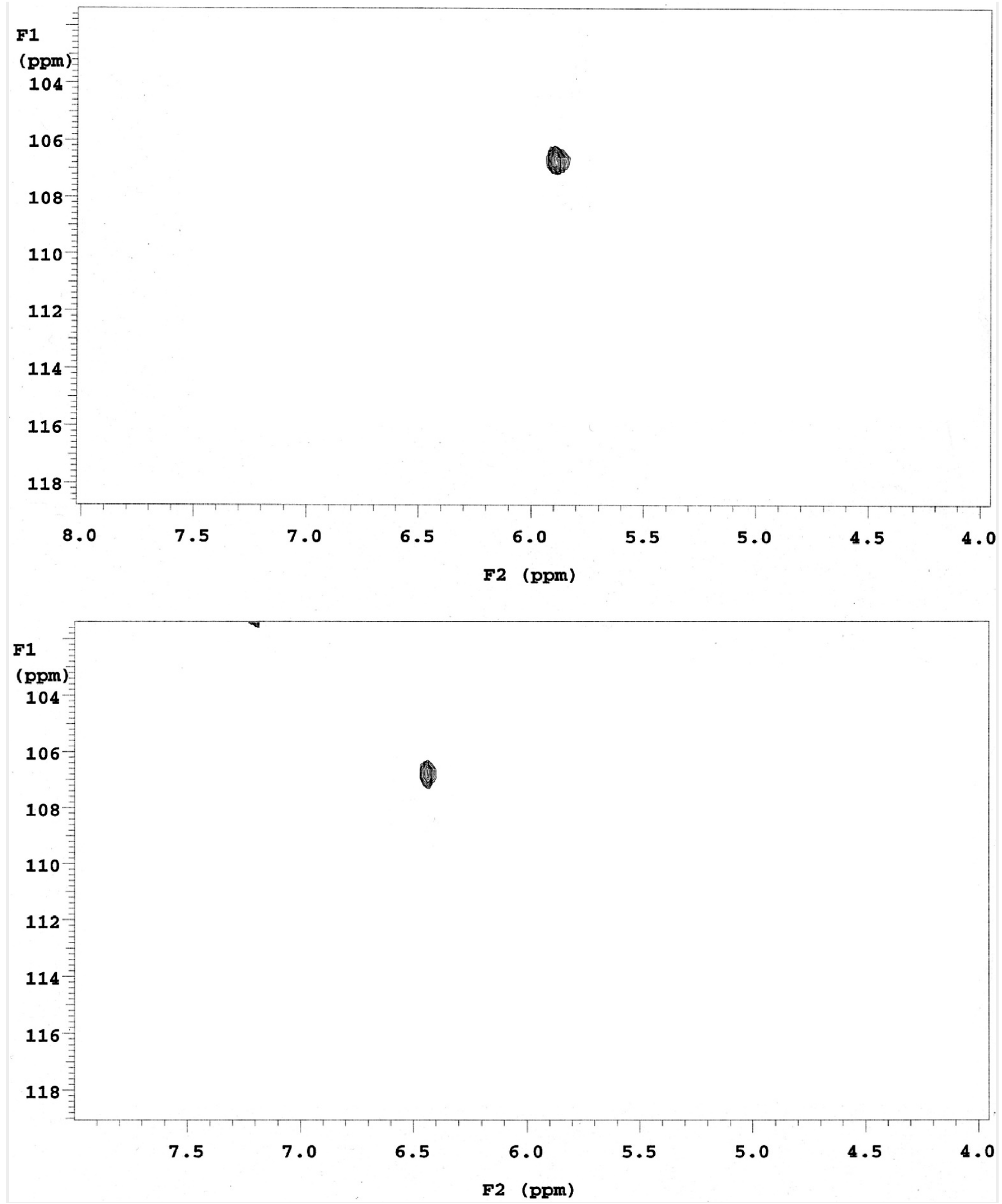

Figure $112 \mathrm{D}{ }^{1} \mathrm{H}\left\{{ }^{15} \mathrm{~N}\right\} \mathrm{HSQC}$ NMR spectra of $(\mathrm{A})$ a mixture of $40 \mathrm{mM}(\boldsymbol{R})-6$ and $40 \mathrm{mM} t \mathrm{BuCQN} \cdot \mathrm{HCl}$; and $(\mathrm{B})$ a mixture of $40 \mathrm{mM}(S)-6$ and $40 \mathrm{mM} t \mathrm{BuCQN} \cdot \mathrm{HCl}$. 
Interestingly, while chiral anions exhibit relatively strong enantiomeric recognition toward the racemic cation $\left((R, S)-2-\mathrm{Me}^{-\mathrm{BMIm}}{ }^{+}\right)$, the reverse is not true; namely, the chiral cation $S-2-\mathrm{Me}-\mathrm{BMIm}{ }^{+}$does not shown any observable chiral recognition toward racemic anions. Figure 7 shows NMR spectra of two samples: sample 1 is $(S)-(S)-8(71.44 \mathrm{mM})$ which is an ionic liquid composed of a chiral anion and a chiral cation, and sample 2 which is a mixture of $(\boldsymbol{S})-(\boldsymbol{R})-8(35.72 \mathrm{mM})$ and $(\boldsymbol{S})-(\boldsymbol{S})-8(35.72 \mathrm{mM})$. This mixture sample corresponds to an ionic liquid with a racemic anion and chiral cation at the same concentration (71.44 mM). As shown in the spectra, they have the same chemical shifts, and there is no splitting for any peaks of the racemic anion.

Intermolecular Chiral Recognition: Chiral Recognition of $t \mathrm{BUCQN} \cdot \mathrm{HCl}$ toward $(S)-6$ and $(R)-6$.

Results presented in the previous section clearly show that the chiral anion of the ILs can exert strong enantiomeric recognition toward the chiral cation. Experiments were then designed to investigate if the chiral recognition is only intramolecularly between the chiral anion and chiral cation (of the IL) or if it can be extended intermolecularly to other chiral molecules. $O$-(tert-Butylcarbamoyl)quinine or $t$ BuCQN (structure below) was selected for this study as it was demonstrated that $t$ BuCQN exhibits relatively strong enantiomeric recognition toward many compounds. In fact, $t$ BuCQN has been successfully used as a chiral selector in various enantiomeric separation techniques, including HPLC, CE, and capillary electrochromatography (CEC). ${ }^{44-49}$ Furthermore, its chiral recognition mechanism has been theoretically investigated and verified experimentally. ${ }^{27,44-49}$ 

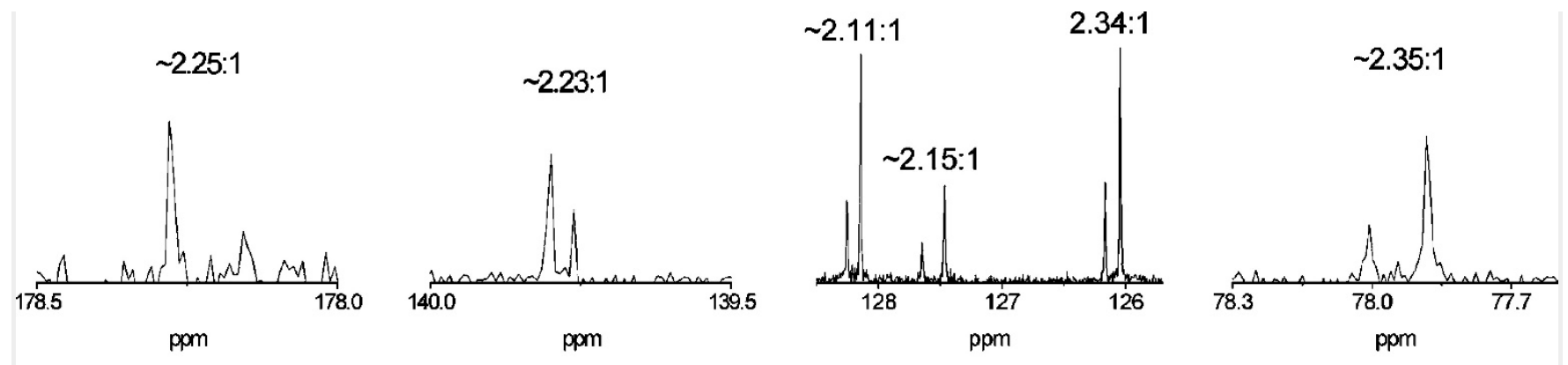

\section{(S) $-2(50 \mathrm{~m} \mathrm{M})$ in $\mathrm{CDCl}_{3}$}

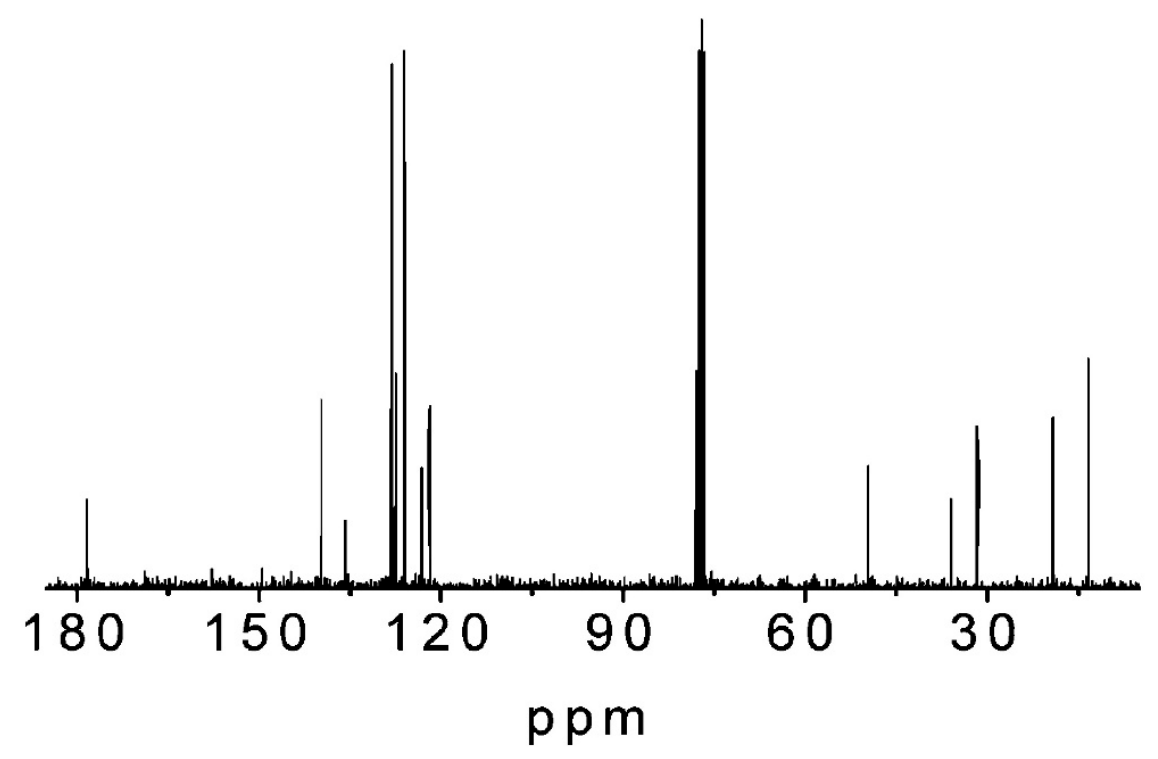

(S) $-2(50 \mathrm{~m} \mathrm{M})$ in $\mathrm{CDCl}_{3}$

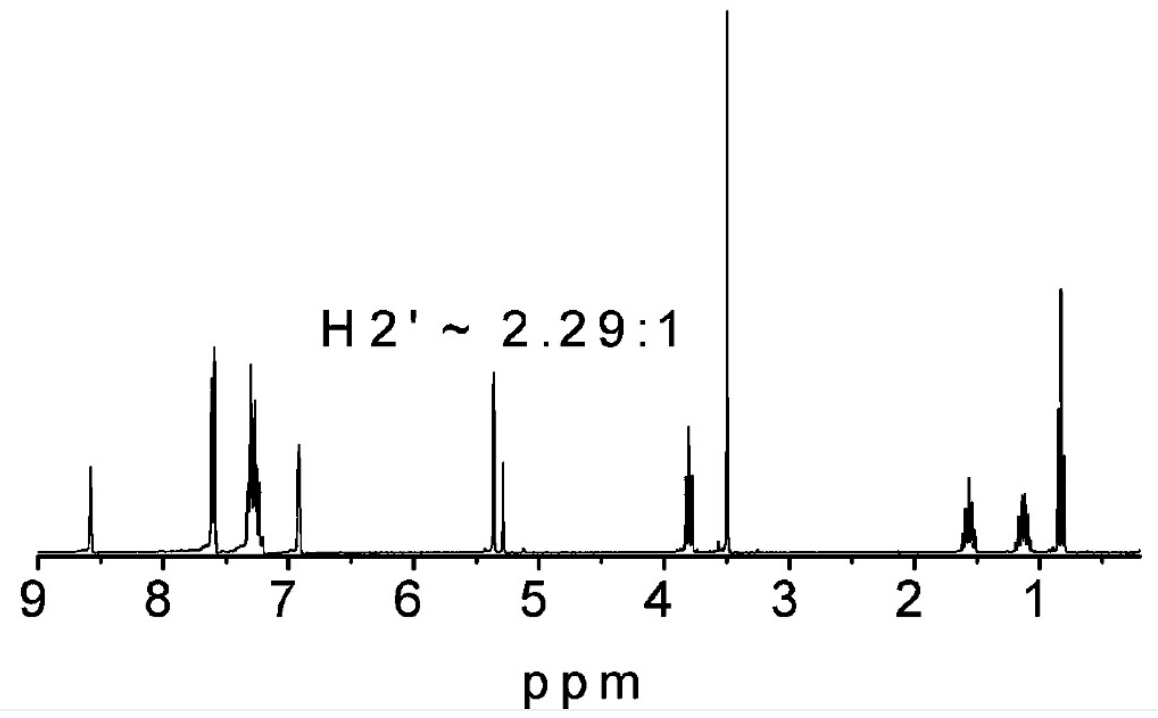

Figure 12 Hydrogen and carbon peak splitting for $(S)-2(50 \mathrm{mM})$ in chloroform with integration ratio labeled. 

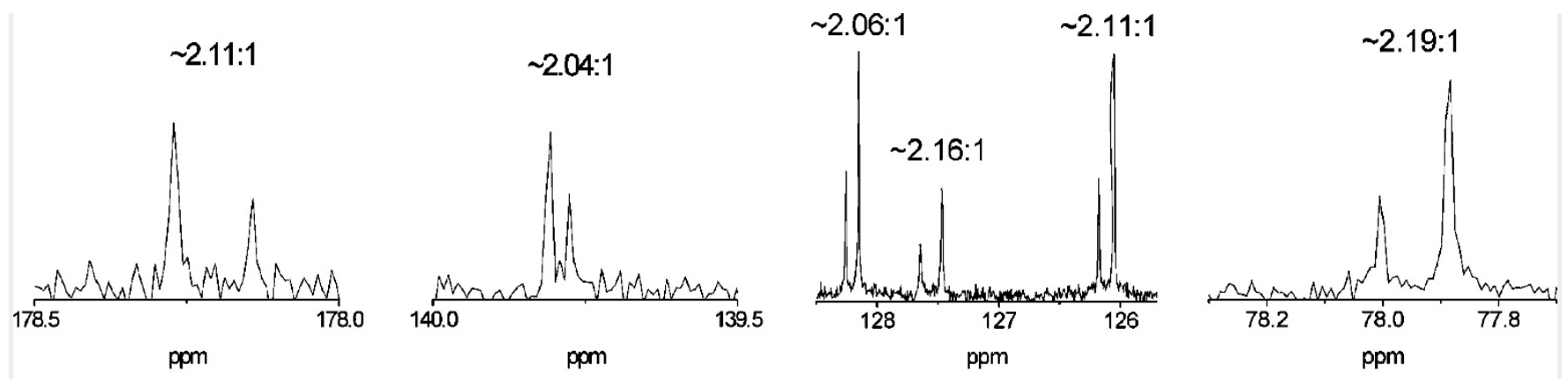

(S) $-(\mathrm{S})-8(50 \mathrm{~m} \mathrm{M})$ in $\mathrm{CDCl}_{3}$

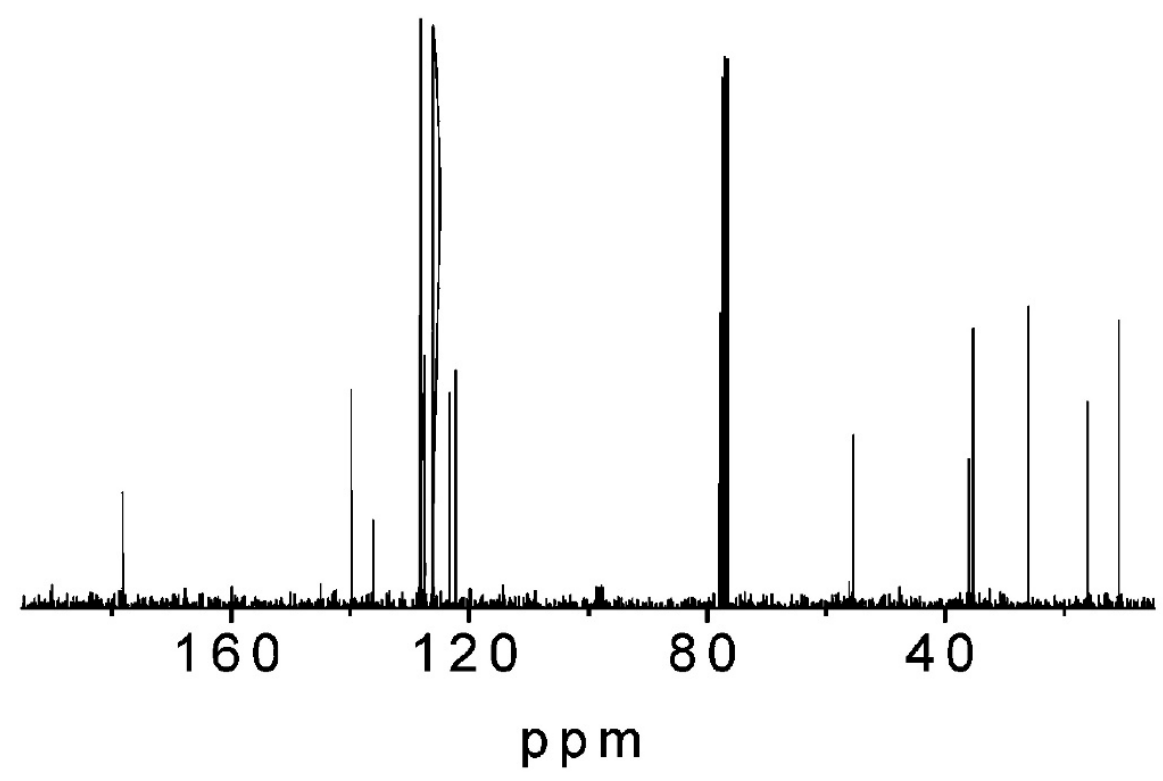

$(\mathrm{S})-(\mathrm{S})-8(50 \mathrm{mM})$ in $\mathrm{CDCl}_{3}$

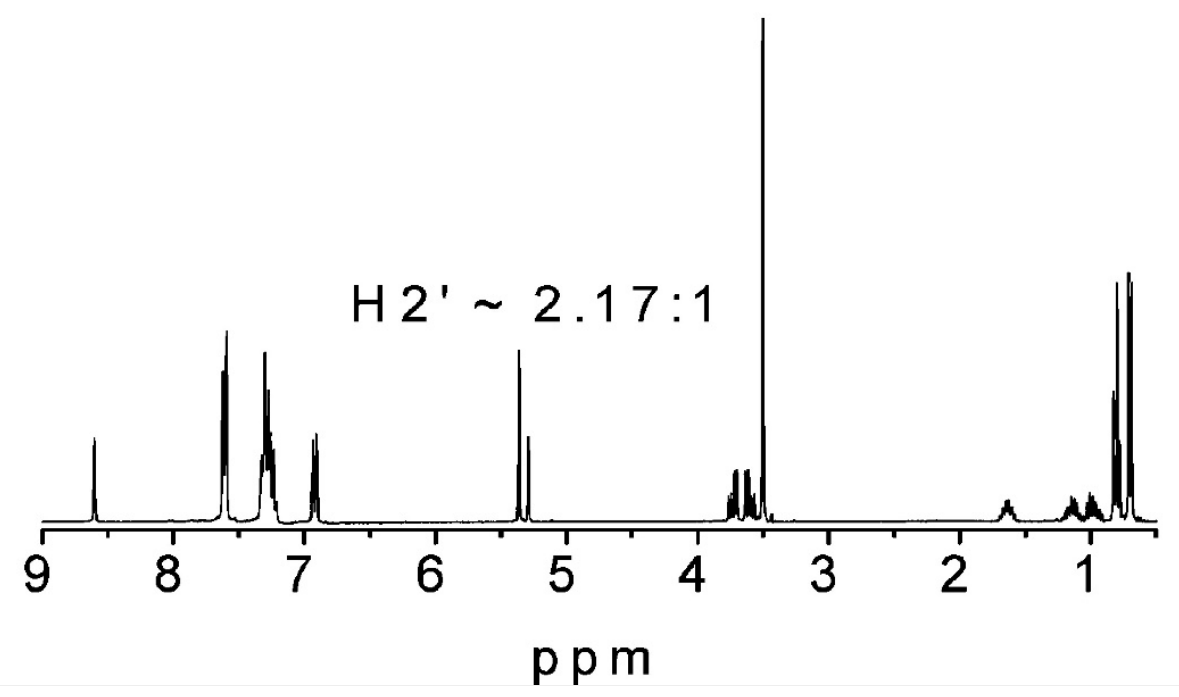

Figure 13 Hydrogen and carbon peak splitting for $(S)-(S)-8(50 \mathrm{mM})$ in chloroform with integration ratio labeled. 


\section{Chemical shift of $\mathrm{H}_{2}$ ' in solvents with different dielectric constant}
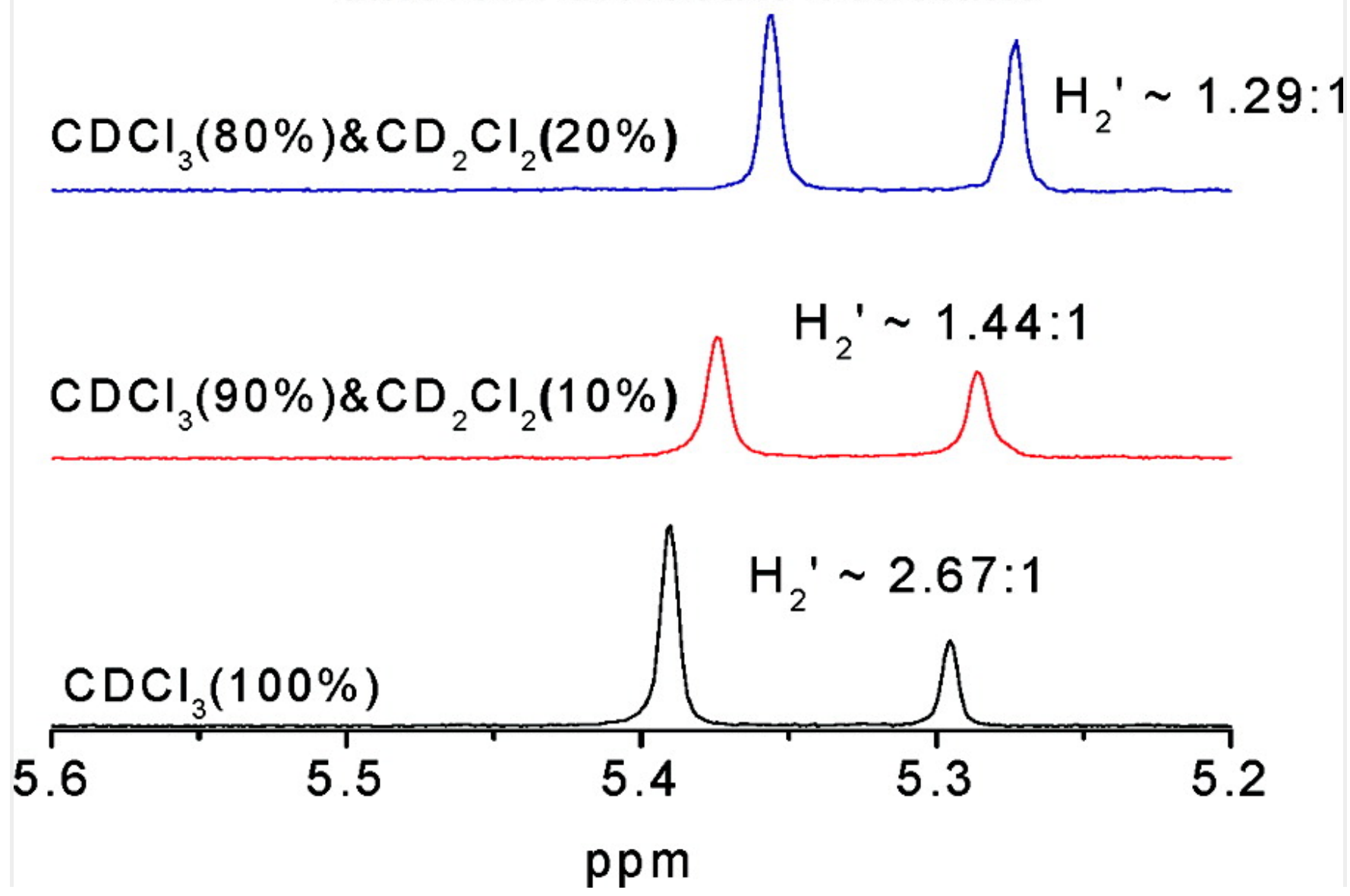

Figure 14 Expanded ${ }^{1} \mathrm{H}$ NMR spectra of $(S)-(R)-8$ in solvents of various dielectric constants. 
A

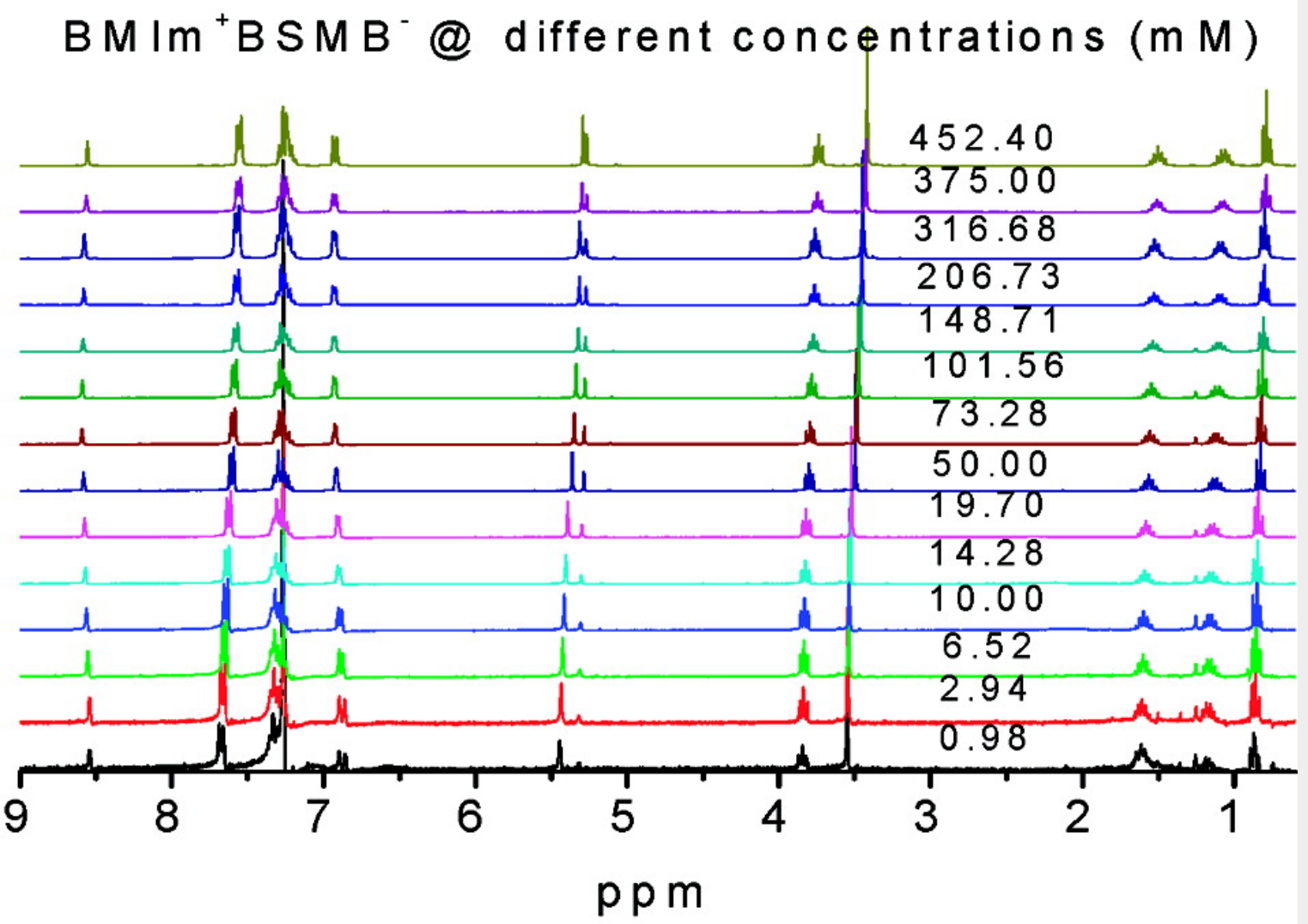

B

$B M I m^{+} B S M B^{-} @$ different concentrations (m M)

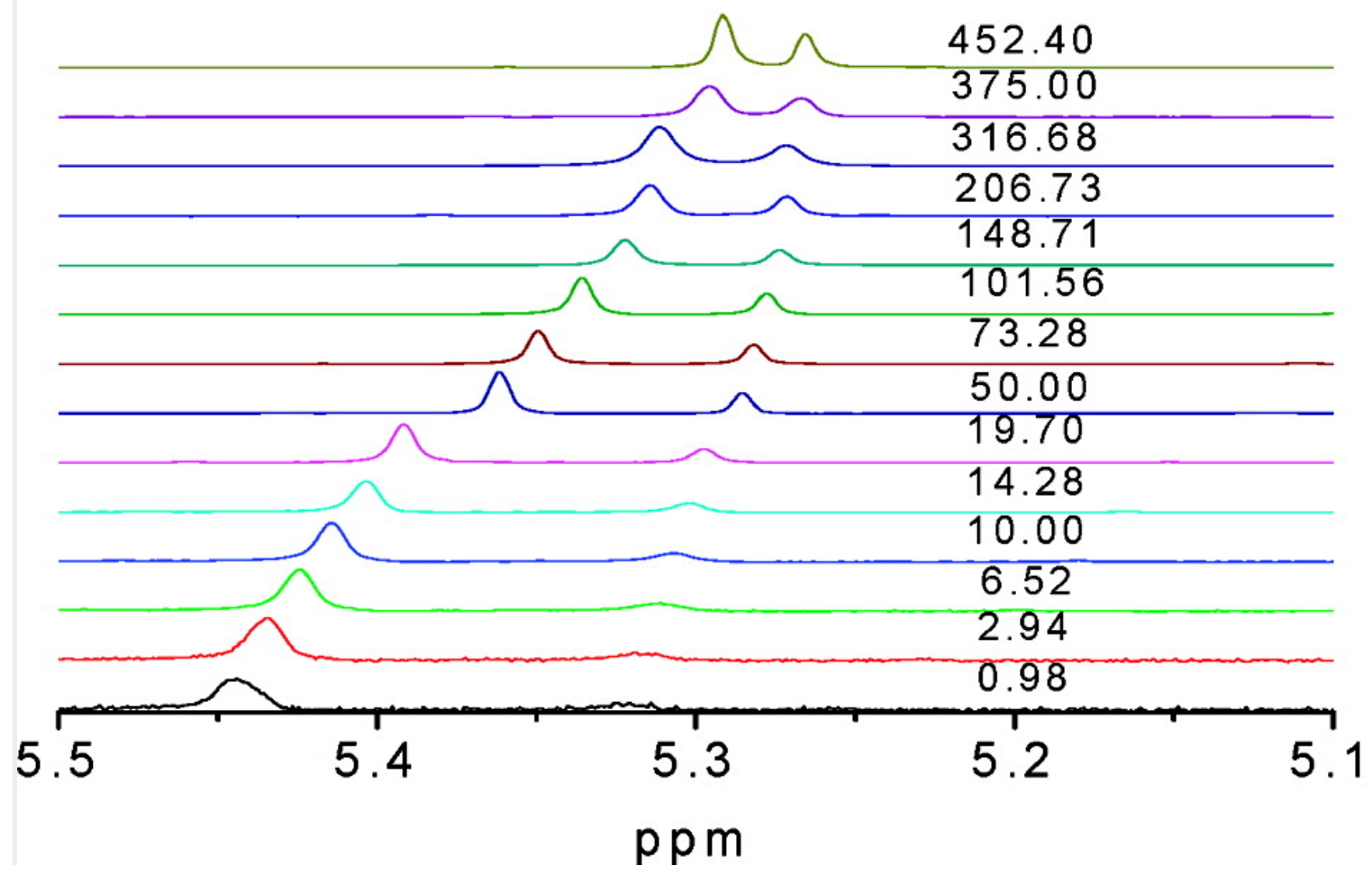

Figure $15(\mathrm{~A}){ }^{1} \mathrm{H}$ NMR and (B) expanded ${ }^{1} \mathrm{H}$ NMR of (S)-2 solutions of different concentrations. 
The initial study was aimed to determine if $t$ BuCQN would have any chiral recogition toward the enantiomeric pair of EMIm ${ }^{+} B M B-$, i.e., $(S)-6$ and $(\boldsymbol{R})-6$. Figure 8 shows NMR spectra of two mixtures: (100 mM of $(\boldsymbol{R})-6+30 \mathrm{mM}$ of $t \mathrm{BuCQN})$ and (100 mM of $(\boldsymbol{S})-6+30 \mathrm{mM}$ of $t$ BuCQN). As illustrated, the two spectra are identical which suggests that under this condition $t$ BuCQN does not exhibit any observable chiral recognition toward the enantiomeric pair of this IL. 

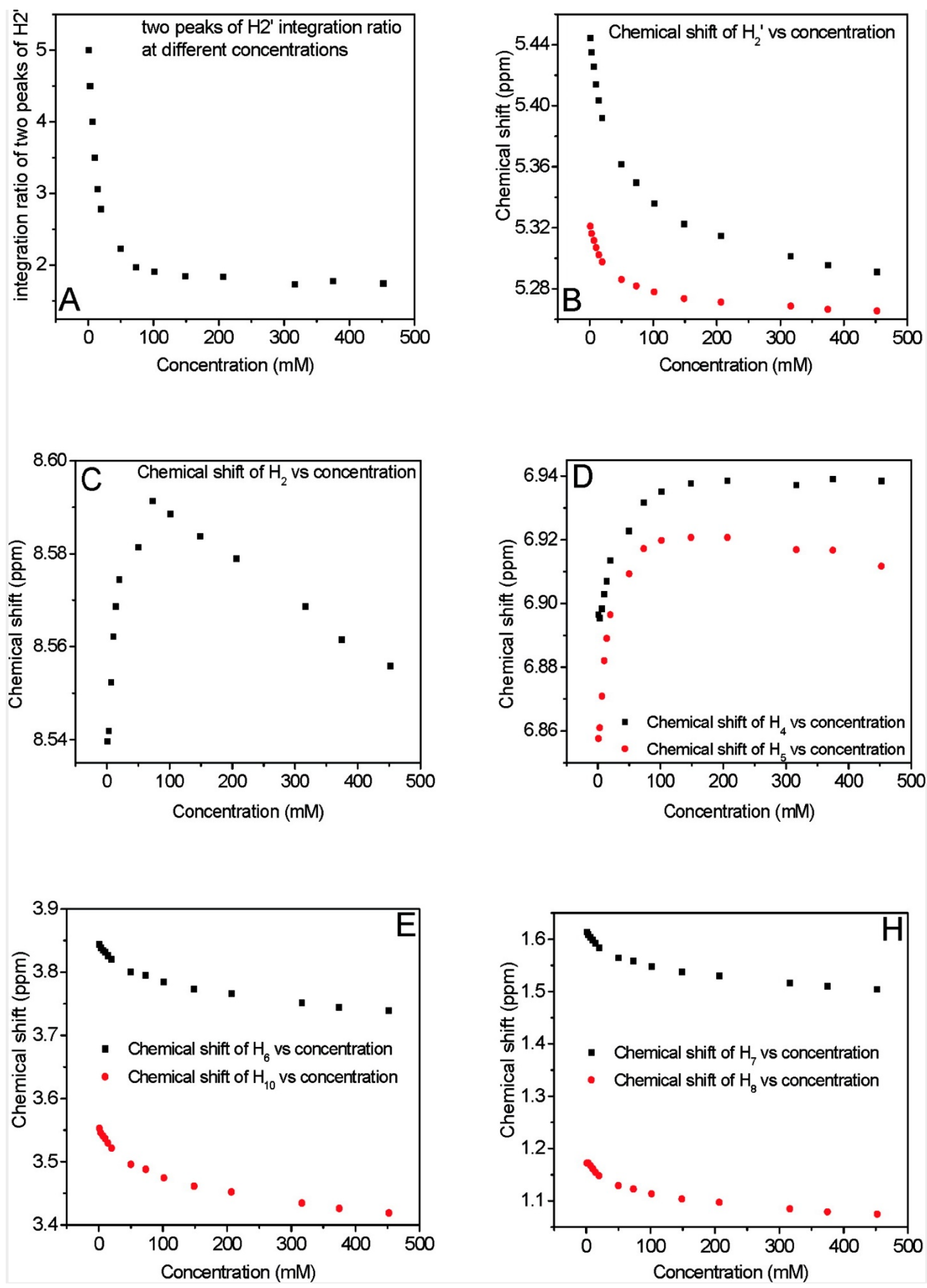

Figure 16 Plots of integration ratio of two peaks of $\mathrm{H}_{2}{ }^{\prime}$ versus concentration and chemical shift of hydrogens of anion vs concentration in chloroform for $(\boldsymbol{S})-\mathbf{2}$. 
Subsequently, $t \mathrm{BuCQN}$ in the free-base form was replaced by its protonated form, $t \mathrm{BuCQN} \cdot \mathrm{HCl}$, and similar experiments were performed. Figure 9 shows NMR spectra of two mixtures: (100 mM of $(\boldsymbol{R})-6+$ $30 \mathrm{mM}$ of $t \mathrm{BuCQN} \cdot \mathrm{HCl}$ ) and $(100 \mathrm{mM}$ of $(S)-6+30 \mathrm{mM}$ of $t \mathrm{BuCQN} \cdot \mathrm{HCl})$. (Bands due to hydrogens of $t \mathrm{BuCQN} \cdot \mathrm{HCl}$ were partially labeled.) Pronounced differences were observed between these two mixtures. For clarity, chemical shifts and chemical shift differences between these two mixtures are partially listed in Table 8. As illustrated, tBuCQN $\cdot \mathrm{HCl}$ undergoes significant chemical shift changes when mixing with $(\boldsymbol{R})-6$ and $(S)-6$. As shown in Figure 9, the positive charge of the protonated quinuclidine moiety (of $t \mathrm{BuCQN} \cdot \mathrm{HCl}$ ) seems to exert strong electrostatic interaction with the anion part of the ionic liquids. This, in turn, brought two molecules closer to produce additional interactions. This deduction stems from careful inspection of chemical shifts and differences. For example, upfield shifts of the aromatic protons of $t \mathrm{BuCQN} \cdot \mathrm{HCl}\left(\mathrm{H}_{2}, \mathrm{H}_{3}, \mathrm{H}_{5}, \mathrm{H}_{1}\right.$, and $\left.\mathrm{H}_{4}\right)$ after interacting with $(\boldsymbol{R})-\mathbf{6}$ and $(\boldsymbol{S})-\mathbf{6}$ seem to indicate that there exists a $\pi-\pi$ interaction between electron-rich quinoline and the electron-deficient imidazolium. ${ }^{50}$ Additionally, there might be hydrogen-bond forming between the hydrogen $\left(\mathrm{H}_{7}\right)$ attached to the amide and the carbonyl groups of the anion because this hydrogen experiences a large downfield shift. And also, there is a steric effect between them as reflected by the fact that the chemical shifts for hydrogens on quinuclidine and on its branch $\left(H_{10}, H_{11}\right.$, and $\left.H_{12}\right)$ also changed.

Figure 9 shows that $(R)-6 / t \mathrm{BuCQN} \cdot \mathrm{HCl}$ and $(S)-6 / t \mathrm{BuCQN} \cdot \mathrm{HCl}$ have different chemical shift changes based on chemical shifts of $t \mathrm{BuCQN} \cdot \mathrm{HCl}$. For example, $\mathrm{H}_{2}$ shifts from 8.834 to $8.734 \mathrm{ppm}$ for $(\boldsymbol{R})$ 6/tBuCQN$\cdot \mathrm{HCl}$ and to $8.595 \mathrm{ppm}$ for $(\boldsymbol{S})-6 / t \mathrm{BuCQN} \cdot \mathrm{HCl}$. $\mathrm{H}_{3}$ shifts from 8.386 to $8.103 \mathrm{ppm}$ for $(\boldsymbol{R})$ 6/tBuCQN$\cdot \mathrm{HCl}$ and to $8.110 \mathrm{ppm}$ for $(S)-6 / t \mathrm{BuCQN} \cdot \mathrm{HCl}$. $\mathrm{H}_{5}$ shifts from 8.028 to $7.734 \mathrm{ppm}$ for $(R)-$ $6 / t \mathrm{BuCQN} \cdot \mathrm{HCl}$ and to $7.75 \mathrm{ppm}$ for $(S)-6 / t \mathrm{BuCQN} \cdot \mathrm{HCl}$. $\mathrm{H}_{7}$ shifts from 5.825 to $6.346 \mathrm{ppm}$ for $(R)$ $6 / t \mathrm{BuCQN} \cdot \mathrm{HCl}$ and to $6.553 \mathrm{ppm}$ for $(\boldsymbol{S})-6 / t \mathrm{BuCQN} \cdot \mathrm{HCl}$. These differences indicate that $(\boldsymbol{R})-$ $6 / t \mathrm{BuCQN} \cdot \mathrm{HCl}$ has different intermolecular interactions from $(S)-6 / t \mathrm{BuCQN} \cdot \mathrm{HCl}$.

Since the natural abundance of ${ }^{15} \mathrm{~N}$ is only $0.37 \%$, the sensitivity of ${ }^{15} \mathrm{~N} N M R$ is relatively low. However, the presence of an amide bond in $t \mathrm{BuCQN} \cdot \mathrm{HCl}$ makes it possible to perform ${ }^{1} \mathrm{H}\left\{{ }^{15} \mathrm{~N}\right\}$ heteronuclear single quantum coherence (HSQC) NMR experiments. ${ }^{51,52}$ This type of experiment makes it possible to observe nitrogen NMR signals with a sensitivity approaching that of protons. ${ }^{51,52}$ The ${ }^{1} \mathrm{H}\left\{{ }^{15} \mathrm{~N}\right\} \mathrm{HSQC}$ NMR spectra were taken at room temperature on Varian $800 \mathrm{MHz}$ using states-TPPI quatrature detection, and the operating $1 \mathrm{H}$ frequency is $799.809 \mathrm{MHz}$ and $15 \mathrm{~N}$ frequency is $81.05 \mathrm{MHz}$. These experiments were performed using the following parameters for the ${ }^{1} \mathrm{H}$ and ${ }^{15} \mathrm{~N}$ dimensions, respectively: sweep widths $16000 \mathrm{~Hz}\left({ }^{1} \mathrm{H}\right)$ and $3000.1 \mathrm{~Hz}\left({ }^{15} \mathrm{~N}\right) ; 4000$ data points $\left({ }^{1} \mathrm{H}\right)$ and 32 data points $\left({ }^{15} \mathrm{~N}\right)$. Because there is only one nitrogen atom attached to hydrogen, it is expected that only one spot in ${ }^{1} \mathrm{H}_{-}{ }^{15} \mathrm{~N}$ 2D spectra will be seen. The 1D spectra (Figure 10) show the chemical shift of the hydrogen which is attached to the nitrogen on the amide group. The chemical shift for this hydrogen is $5.911 \mathrm{ppm}$ for solution containng only $40 \mathrm{mM} \mathrm{tBuCQN} \cdot \mathrm{HCl}$ (bottom spectrum). It is shifted to 6.452 ppm when $(\boldsymbol{R})-\mathbf{6}$ is added to the solution, i.e., for solutions containing $40 \mathrm{mM}(\boldsymbol{R})-\mathbf{6}$ and 40 $\mathrm{mM} t \mathrm{BuCQN} \cdot \mathrm{HCl}$ (middle spectrum). Replacing (R)-6with (S)-6 (solution containing $40 \mathrm{mM}(\boldsymbol{S})-6$ and 40 $\mathrm{mM} t \mathrm{BuCQN} \cdot \mathrm{HCl}$ ) shifted the band to $6.700 \mathrm{ppm}$ (top spectrum). The $2 \mathrm{D}{ }^{1} \mathrm{H}\left\{{ }^{15} \mathrm{~N}\right\} \mathrm{HSQC}$ spectra were shown in Figure 11. The result clearly confirms that $t \mathrm{BuCQN} \cdot \mathrm{HCl}$ exhibits different interactions with (S)6 and $(\boldsymbol{R})-6$; i.e., $t$ BuCQN$\cdot \mathrm{HCl}$ exhibits strong enantiomeric recognition toward $(\boldsymbol{S})-\mathbf{6}$ and $(\boldsymbol{R})-\mathbf{6}$. 


\section{A}

S-2-Me-BMIm ${ }^{+} \mathrm{BSMB}^{-} @$ all condentrations (m M)

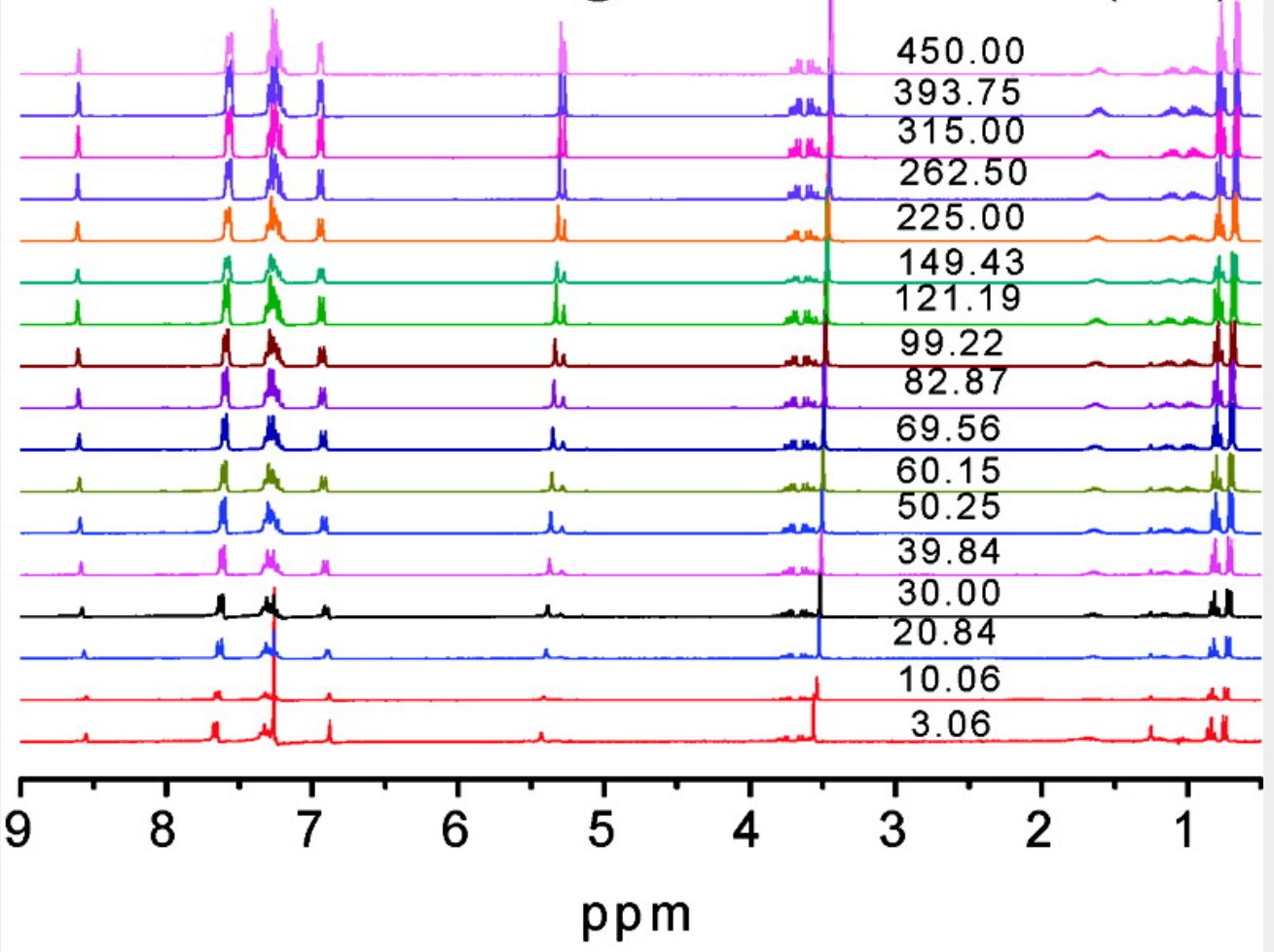

$B$

S-2-Me-BMIm ${ }^{+} \mathrm{BSMB}^{-} @$ all concentrations (m M)

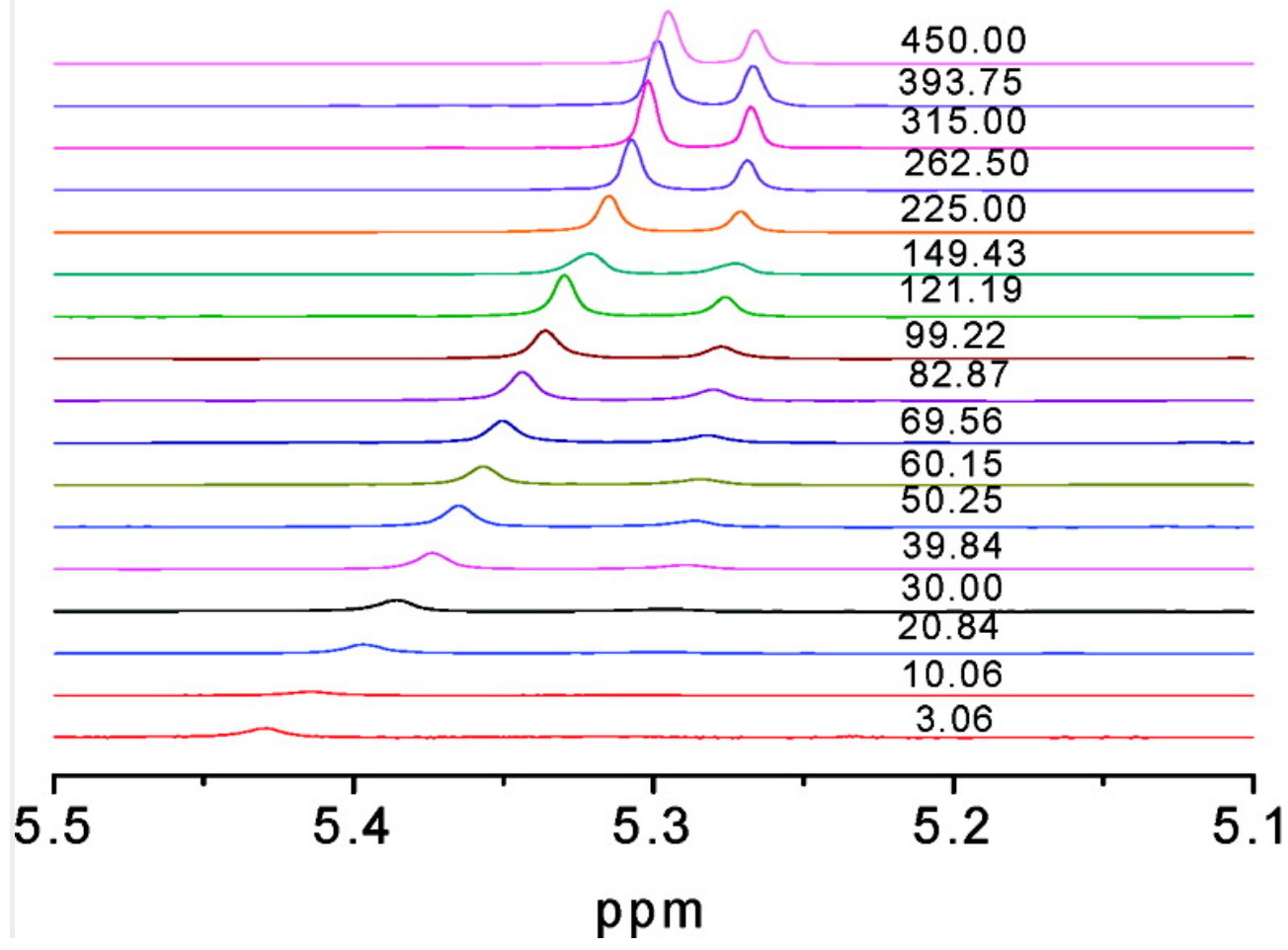

Figure $17(\mathrm{~A}){ }^{1} \mathrm{H}$ NMR and (B) expanded ${ }^{1} \mathrm{H}$ NMR of $(S)-(S)-8$ solutions of different concentrations. 

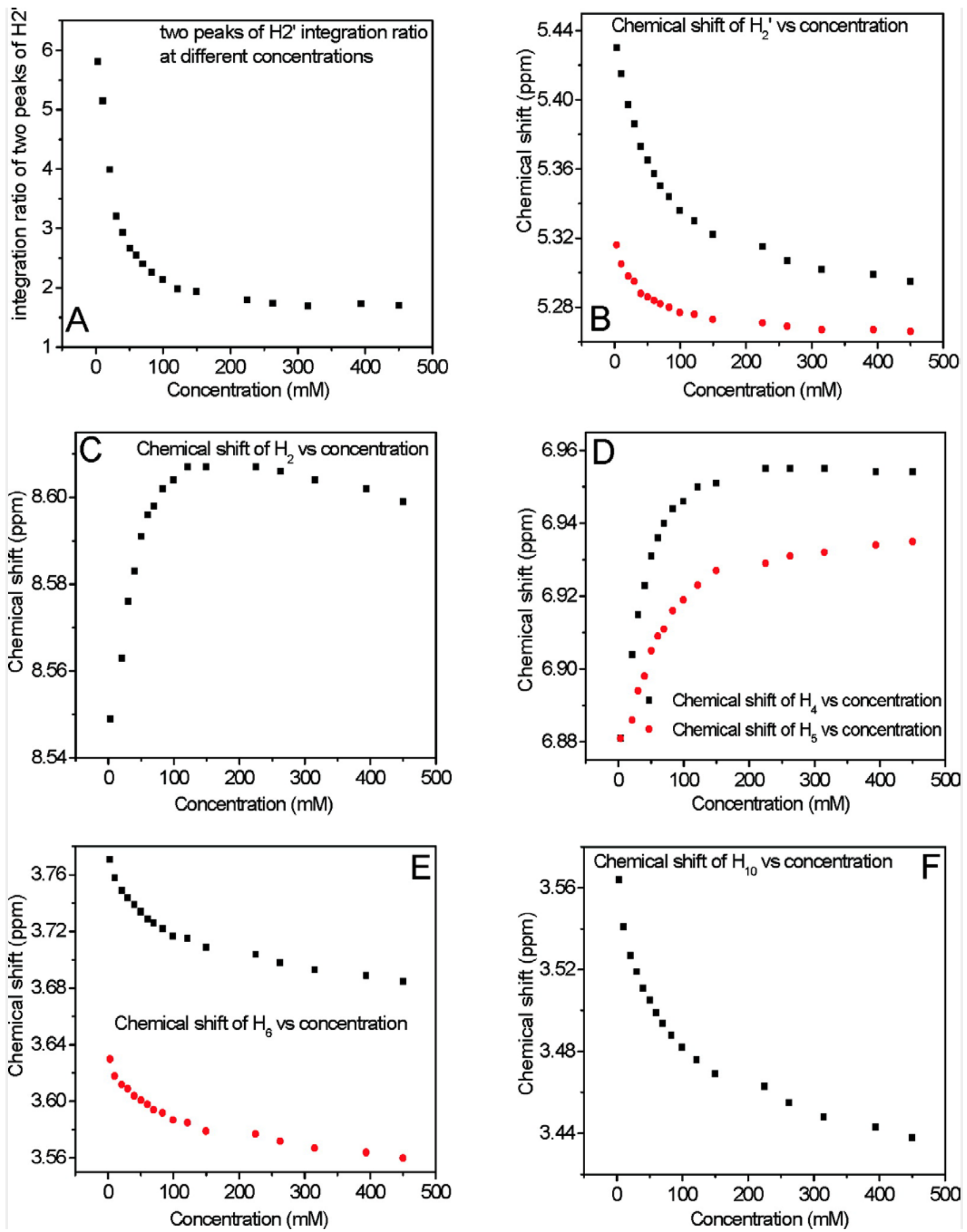

Figure 18 Plots of integration ratio of two peaks of $\mathrm{H}_{2}{ }^{\prime}$ versus concentration and chemical shift of hydrogens of anion versus concentration in chloroform for $(S)-(S)-8$. 


\section{Chemical States of Ionic Liquids in Solution.}

${ }^{1} \mathrm{H} N M R$ and ${ }^{13} \mathrm{C}$ NMR spectra of synthesized chiral ionic liquids seem to be more complicated compared to those expected from their structures. Carefully inspecting both ${ }^{1} \mathrm{H}$ and ${ }^{13} \mathrm{C}$ NMR spectra reveals that there are, in fact, two sets of resonances for hydrogens and carbons of the anions. The splitting ratio of hydrogen is the same as that of carbon within experimental error (Figures 12 and 13). For a solution of $50.0 \mathrm{mM}(S)-2$ in chloroform, the splitting ratio for $\mathrm{H}_{2}{ }^{\prime}$ is 2.29:1, and those for carbons are 2.25:1, 2.23:1, 2.11:1, 2.15:1, 2.34:1, and 2.35:1. Similarly, for (S)-(S)-8 (50 mM in chloroform), the splitting ratio for $\mathrm{H}_{2}{ }^{\prime}$ is 2.17:1, and those for carbons are 2.11:1, 2.04:1, 2.06:1, 2.16:1, 2.11:1, and 2.19:1. (It it relatively difficult to evaluate other hydrogens because their bands are severely overlapped among one another.) Furthermore, it was found that the ratio of these two sets of resonances depends not only on the properties of the solvent but also on the concentration of the ionic liquid. Specifically, in a solvent with low dielectric constant, a higher splitting ratio was observed. Take $(\boldsymbol{S})-(\boldsymbol{R})-\mathbf{8}$ for an example. Its expanded ${ }^{1} \mathrm{H}$ NMR spectra in solvents of varying dielectric constants were shown in Figure 14. Mixtues of dichloromethane and chloroform with different volume ratios were used to produce solvents with different dielectric constants. As illustrated, the splitting ratio for $\mathrm{H}_{2}{ }^{\prime}$ decreases from 2.67:1 to 1.29:1 when the dielectric constant increases from 4.8 to 5.66. The splitting ratio becomes larger when the concentration of the ionic liquid was decreased (from 452.40 to $0.98 \mathrm{mM}$ ) (see, for example, Figures 15A, 16A, 17B, and 18A). For (S)-2, the splitting ratio of $\mathrm{H}_{2}{ }^{\prime}$ changed from a value of 5 for the $0.98 \mathrm{mM}$ solution to 2.23 for the $50.00 \mathrm{mM}$ solution to 1.745 for a solution of $452.40 \mathrm{mM}$. Similarly, for $(S)-(S)-8$, the splitting ratio of $\mathrm{H}_{2}$ ' decreased from $5.81(3.06 \mathrm{mM}$ solution) to $2.40(69.56 \mathrm{mM})$ to $1.70(450.00 \mathrm{mM})$. Taken together, the results seem to suggest that the anions may not exist entirely in monomeric form in solution. Chemical shift versus ionic liquid concentration and splitting ratio of $\mathrm{H}_{2}{ }^{\prime}$ versus concentration of ionic liquid in chloroform were then plotted to gain more insight into the nature of these forms. As illustrated in Figures 16A-F and 18A-F, all of the plots exhibit abrupt changes at a certain concentration range. These abrupt changes are more pronounced in some plots such as Figures 16A, 16C, 16D, 18A, 18C, and 18D. These abrupt changes are similar to those observed for surfactants in solutions and seem to suggest that the ionic liquids may undergo aggregation in solution when their concentrations reach a certain range. The concentration range was found to be from 50 to $100 \mathrm{mM}$ in chloroform for $(S)-2$ and from 70 to $120 \mathrm{mM}$ in chloroform for $(S)-(S)-8$. The observation of two different dominating species present in the solution at different concentration ranges is, in fact, agreement with the monomeric and aggregated forms. It is pleasing to see that splitting ratio of $\mathrm{H}_{2}$ ' versus concentration also shows the same trend as chemical shift versus concentration (Figures $16 \mathrm{~A}$ and 18A). And the abrupt changes that appear at the same concentration range for different plots of two sets of resonances in ${ }^{1} \mathrm{H} N M R$ and ${ }^{13} \mathrm{C}$ NMR spectra again confirm the conclusion that they are from the monomeric and aggregated form of the ionic liquids. It is noteworthy to add that aggregation of ionic liquids in solutions is not specific to only the ionic liquids synthesized in this work. It has, in fact, been previously found that other ionic liquids including those based on alkylmethylimidazolium and $N$-alkyl- $N$-methylpyrrolidinium behave like surfactants in solutions; namely, they undergo aggregation in solutions. ${ }^{7,53-55}$

\section{Conclusions}

In summary, a series of structurally novel chiral ionic liquids which have either chiral cation, chiral anion, or both have been successfully synthesized. Cations are an imidazolium group, while anions are based on the borate ion with spiral structure and chiral substituents. Both (or all) stereoisomeric forms 
of each compound in the series can be readily synthesized in optically pure form by a simple one-step process from commercially available reagents. In addition to the ease of preparation, most of the chiral ILs in this series are liquid at room temperature, with a solid to liquid transformation temperature as low as $-70^{\circ} \mathrm{C}$, and have relatively high thermal stability (up to at least $300^{\circ} \mathrm{C}$ ). Circular dichroism and $\mathrm{X}$-ray crystallographic results confirm that the reaction to form the chiral spiral borate anion is stereospecific; namely, only one of two possible spiral stereoisomers was formed. Results of NMR studies including ${ }^{1} \mathrm{H}\left\{{ }^{15} \mathrm{~N}\right\}$ heteronuclear single quantum coherence (HSQC) show that these chiral ILs exhibit intramolecular as well as intermolecular enantiomeric recognition. Intramolecularly, the chiral anion of an IL was found to exhibit chiral recognition toward the cation. Specifically, for a chiral IL composing with a chiral anion and a racemic cation, enantiomeric recognition of the chiral anion toward both enantiomers of the cation lead to pronounced differences in the NMR bands of the cation enantiomers. The chiral recognition was found to be dependent on solvent dielectric constant, concentration, and structure of the ILs. Stronger enantiomeric recognition was found in solvent with relatively lower dielectric constants $\left(\mathrm{CDCl}_{3}\right.$ compared to $\left.\mathrm{CD}_{3} \mathrm{CN}\right)$ and at a higher concentration of ILs. Also stronger chiral recognition was found for an anion with a relatively larger substituent group (e.g., a chiral anion with a phenylmethyl group exhibits stronger chiral recognition compared to that with a phenyl group, and an anion with an isobutyl group has the weakest chiral recognition). Chiral anions were also found to exhibit intermolecular chiral recognition. Enantiomeric discrimination was found for a chiral IL composed of a chiral anion and achiral cation toward another chiral molecule such as a quinine derivative. Structurally novel and strong intra- and intermolecular chiral recognition ability of these chiral ILs indicate that they can be used in a variety of applications including as chiral solvent for asymmetric synthesis and as chiral stationary phase for chromatographic separations. These possibilities are the subject of our current intense investigation.

\section{Experimental Section}

Chemicals. Methylimidazole, 1-chlorobutane, bromoethane, $(S)-(+)-1-$ bromo-2-methylbutane, 1chloro-2-methylbutane, lithium carbonate, boric acid, L-(+)-lactic acid solution $(85 \%+)$, $R$-mandelic acid, $S$-mandelic acid, $(R)-(-)$-hexahydromandelic acid, $(S)-(+)$-hexahydromandelic acid, and quinine were used as obtained from the manufacturer. D-(-)-Lactic acid, L- $\alpha$-hydroxyisocaproic acid, D- $\alpha-$ hydroxyisocaproic acid, L- $\alpha$-hydroxyisovaleric acid, D- $\alpha$-hydroxyisovaleric acid, L- $\beta$-phenyllactic acid, and D- $\beta$-phenyllactic acid were purchased from various manufacturers.

Methods. O-(tert-Butylcarbamoyl) quinine (tBuCQN) was synthesized using a previously reported procedure. ${ }^{27,28} \mathrm{O}$-(tert-Butylcarbamoyl)quinine $\cdot \mathrm{HCl}$ or $t \mathrm{BuCQN} \cdot \mathrm{HCl}$ was prepared from $t \mathrm{BuCQN}$. They were characterized using ${ }^{1} \mathrm{H}$ and ${ }^{13} \mathrm{C}$ NMR. The complete synthesis procedure and NMR spectra of these compounds are included in the Supporting Information.

All of the ILs synthesized were characterized using ${ }^{1} \mathrm{H},{ }^{13} \mathrm{C}$, and ${ }^{11} \mathrm{~B} \mathrm{NMR}$ (taken at room temperature on a $300 \mathrm{MHz}$ spectrometer at 300,75 , and $96 \mathrm{MHz}$ (with $\mathrm{BF}_{3} \cdot \mathrm{Et}_{2} \mathrm{O}$ in $\mathrm{CDCl}_{3}$ as external reference), respectively), thermal gravimetric analysis (TGA), and electrospray ionization (ESI) mass spectrometry, differential scanning calorimetry (DSC), and circular dichroism spectropolarimeter. The spectra are included in the Supporting Information.

In the thermal gravimetric analysis (TGA), to avoid any possible reaction between ionic liquids and the sample crucible made from quartz or aluminum at elevated temperature, ${ }^{29,30}$ we lined the quartz crucibles with silver foil before placing the sample into it. The sample size was in the ( $\sim 0$ to 60$) \mathrm{mg}$ range. Measurements were performed under a flowing nitrogen atmosphere (at a flow rate of 80 
$\mathrm{mL} / \mathrm{min}$ ) at a scan rate of $20^{\circ} \mathrm{C} / \mathrm{min}$ from 20 to $700{ }^{\circ} \mathrm{C}$. All TGA results are the average of at least three measurements. The temperature reproducibility of the TGA is $\pm 3^{\circ} \mathrm{C}$, and the error range of the nonvolatile fraction at $700{ }^{\circ} \mathrm{C}$ is $\pm 3^{\circ} \mathrm{C}$.

Differential scanning calorimetric (DSC) measurements were performed using a differential scanning calorimeter. Optical rotation was determined on a polarimeter at $589 \mathrm{~nm}$ at room temperature. A spectropolarimeter was used to record CD spectra. Electrospray mass spectra were taken on an ESI-MS instrument.

Crystal structures were determined by single-crystal X-ray diffraction using a diffractometer equipped with an APEX CCD detector with graphite-monochromated Mo-K $\alpha$ radiation $(\lambda=0.71073 \AA)$ at a temperature of $100 \pm 2{ }^{\circ} \mathrm{K}$ (except in the case of $\mathrm{D}-5$ where $\mathrm{Cu}-\mathrm{K} \alpha$ radiation $(\lambda=1.54178 \AA$ ) was used to determine its absolute configuration). The structures were solved by direct methods using the available program ${ }^{31}$ and were refined with full-matrix least-squares on $\mathrm{F}^{2}$ techniques. ${ }^{32}$ Non-hydrogen atoms were refined freely with anisotropic displacement parameters, and hydrogen atoms were refined as rigid groups. For $S-2-M e-B M I m^{+} B^{2} \mathrm{HvB}^{-}$, the (S)-2-methylbutyl group was refined with a disorder model. Detailed information on the crystal structure determinations is provided in the Supporting Information.

\section{Acknowledgment}

The authors would like to acknowledge Dr. Patrick Ting of the Miller Brewing Company for his help and for the use of circular dichroism and the mass spectrometer and Prof. Daniel Sem for his competent assistance with NMR measurements. Acknowledgment is also made to Prof. Andrea Mele of Politecnico di Milano, Italy for his help and stimulated discussion.

\section{References}

${ }^{1}$ Welton, T. Chem. Rev. 1999, 99, 2071-2083.

${ }^{2}$ Wasserscheid, P., Welton, T., Eds. Ionic Liquids in Synthesis; Wiley-VCH: Weinheim, Germany, 2003.

${ }^{3}$ Ohno, H., Eds. Electrochemical Aspects of lonic Liquids; Wiley: New York, 2005.

${ }^{4}$ Tundo, P.; Perosa, A. Chem. Soc. Rev. 2007, 36, 532-550.

${ }^{5}$ Tran, C. D.; Lacerda, S. H. P. Anal. Chem. 2002, 74, 5337-5341.

${ }^{6}$ Tran, C. D.; Lacerda; S. H. P.; Oliveira, D. Appl. Spectrosc. 2003, 57, 152-157.

${ }^{7}$ Mele, A.; Tran, C. D.; Lacerda, S. H. P. Angew. Chem., Int. Ed. 2003, 42, 4364-4366.

${ }^{8}$ Blanchard, L. A.; Hancu, D.; Beckman, E. J.; Brennecke, J. F. Nature 1999, 399, 28-29.

${ }^{9}$ Huddleston, J. G.; Willauer, R. P.; Swatloski, A. E.; Visser, A. E.; Rogers, R. D. Chem. Commun. 1998, 1765-1766.

Blanchard, L. A.; Brennecke, J. F. Ind. Eng. Chem. Res. 2001, 40, 287-292.

${ }^{11}$ Quinn, B. M.; Ding, Z.; Moulton, R.; Bard, A. J. Langmuir 2002, 18, 1734-1742.

${ }^{12}$ Mwongela, S. M.; Numan, A.; Gill, N. L.; Agbaria, R. A.; Warner, I. M. Anal. Chem. 2003, 75, 6089-6096.

${ }^{13}$ Tran, C. D.; Challa, S.; Franko, M. Anal. Chem. 2005, 77, 7442-2447.

${ }^{14}$ Earle, M. J.; McCormac, P. B.; Seddon, K. R. Green Chem. 1999, 1, $23-28$.

${ }^{15}$ Wasserscheid, P.; Bosmann, A.; Bolm, C. Chem. Commun. 2002, 200-201.

${ }^{16}$ Levillain, J.; Dubant, G.; Abrunhosa, I.; Gulea, M.; Gaumont, A. C. Chem. Commun. 2003, 2914-2915.

${ }^{17}$ Fukumoto, K.; Yoshizawa, M.; Ohno, H. J. J. Am. Chem. Soc. 2005, 127, 2398-2399.

${ }^{18}$ Ding, J.; Desikan, V.; Han, X.; Xiao, T. L.; Ding, R.; Jenks, W. S.; Armstrong, D. W. Org. Lett. 2005, 7, 335-337.

${ }^{19}$ Baudequin, C.; Baudoux, J.; Levillain, J.; Cahard, D.; Gaumont, A.; Plaquevent, J. Tetrahedron: Asymmetry2003, 14, 3081.

Bao, W.; Wang, Z.; Li, Y. J. Org. Chem. 2003, 68, 591.

${ }^{21}$ Ishida, Y.; Miyauchi, H.; Saigo, K. Chem. Commun. 2002, 2240. 
${ }^{22}$ Vo-Thanh, G.; Pegot, B.; Loupy, A. Eur. J. Org. Chem. 2004, 5, 1112.

${ }^{23}$ Pegot, B.; Vo-Thanh, G.; Gori, D.; Loupy, A. Tetrahedron Lett. 2004, 45, 6425.

${ }^{24}$ Howarth, J.; Hanlon, K.; Fayne, D.; McCormac, P. Tetrahedron Lett. 1997, $38,3097$.

${ }^{25}$ Tran, C. D.; Oliveira, D.; Yu, S. Anal. Chem. 2006, 78, 1349-1356.

${ }^{26}$ Tran, C. D.; Oliveira, D. Anal. Biochem. 2006, 356, 51-58.

${ }^{27}$ Tran, C. D., Yu, S. J. Phys. Chem. B 2005, 109 (25), 12627-12635.

${ }^{28}$ Linder, W.; Lammerhofer, M.; Maier, N. M., PCT/EP97/02888, 1997.

${ }^{29}$ Ngo, H. L.; LeCompte, K.; Hargens, L.; McEwen, A. B. Thermochim. Acta 2000, 357-358, 97-105.

Kosmulski, M.; Gustafsson, J.; Rosenholm, J. B. Thermochim. Acta 2004, 412, 47-55.

${ }^{31}$ Sheldrick, G. M. SHELXS-97, Program for Crystal Structure Solution; University of Göttingen: Germany, 1997.

${ }^{32}$ Sheldrick, G. M. SHELXS-97, Program for Crystal Structure Refinement; University of Göttingen: Germany, 1997.

${ }^{33}$ Zhao, D. Aust. J. Chem 2004, 57, 509-510.

${ }^{34}$ Del Popolo, M. G.; Lynden-Bell, R. M.; Kohanoff, J. J. Phys. Chem. B 2005, 109 (12), 5895-5902.

${ }^{35}$ Talaty, E. R.; Raja, S.; Storhaug, V. J.; Dolle, A.; Carper, W. R. J. Phys. Chem. B 2004, 108 (35), 13177-13184.

${ }^{36}$ Choudhury, A. R.; Winterton, N.; Steiner, A.; Cooper, A. I.; Johnson, K. A. J. Am. Chem. Soc. 2005, 127(48), 16792-16793.

${ }^{37}$ Chang, H.; Jiang, J.; Tsai, W.; Chen, G.; Lin, S. J. Phys. Chem. B 2006, 110 (7), 3302-3307.

${ }^{38}$ Wang, X.; Woo, H.; Kiran, B.; Wang, L. Angew. Chem., Int. Ed. 2005, 44 (31), 4968-4972.

${ }^{39}$ Steiner, T.; Saenger, W. J. Am. Chem. Soc. 1992, 114 (26), 10146-10154.

Jeffery, G. A. An Introduction to Hydrogen Bonding; New York: Oxford University Press, 1997.

${ }^{41}$ Cahn, R. S.; Ingold, C.; Prelog, V. Angew. Chem., Int. Ed. Engl. 1966, 5 (4), 385-415.

${ }^{42}$ Lacour, J.; Hebbe-Viton, V. Chem. Soc. Rev. 2003, 32 (6), 373-382.

${ }^{43}$ Green, S.; Nelson, A.; Warriner, S.; Whittaker, B. J. Chem. Soc., Perkin Trans. 1 2000, 24, 4403-4408.

${ }^{44}$ Piette, V.; Lindner, W.; Crommen, J. J. Chromatogr. A 2000, 894, 63-71.

${ }^{45}$ Piette, V.; Lindner, W.; Crommen, J. J. Chromatogr. A 2002, 948, 295-302.

${ }^{46}$ Oberleitner, W. R.; Maier, N. M.; Lindner, J. Chromatogr. A 2002, 960, 97-108.

${ }^{47}$ Piette, V.; Lämmerhofer, M.; Lindner, W.; Crommen, J. J. Chromatogr. A 2003, 987, 421-427.

${ }^{48}$ Lämmerhofer, M.; Peters, E. C.; Yu, C.; Svec, F.; Frechet, J. M. J.; Lindner, W. Anal. Chem. 2000, 72 (19), 4614-4622.

${ }^{49}$ Lämmerhofer, M.; Svec, F.; Frechet, J. M. J.; Lindner, W. Anal. Chem. 2000, 72 (19), 4623-4628.

Jung, D.; De Ropp, J. S.; Ebeler, S. E. J. Agric. Food Chem. 2000, 48 (2), 407-412.

${ }^{51}$ Pintacuda, G.; Huber, T.; Keniry, M. A.; Park, A. Y.; Dixon, N. E.; Otting, G. Mod. Magnon. Res. 2006, 2, 1245-1251.

${ }^{52}$ Xia, C.; Forsterling, F. H.; Petering D. H. Biochemistry, 2003, 42, 6559-6564.

${ }^{53}$ Tran, C. D.; Yu, S. J. Colloid Interface Sci. 2005, 283, 613-618.

${ }^{54}$ Dong, B.; Li, N.; Wheng, L.; Yu, L.; Inoue, T. Langmuir 2007, 23, 4178-4182.

${ }^{55}$ Vanyur, R.; Biczok, L.; Miskolczy, Z. Colliods Surf., A 2007, 299, 256-261. 